\title{
New approaches to surgery for breast cancer
}

\section{S E Singletary}

The University of Texas M D Anderson Cancer Center, Department of Surgical Oncology, Houston, Texas, USA

(Requests for offprints should be addressed to Department of Surgical Oncology, The University of Texas M D Anderson Cancer Center, 1515 Holcombe Boulevard, Box 444, Houston, Texas 77030, USA)

\begin{abstract}
The surgical management of breast cancer is rapidly evolving towards less invasive procedures. Alternative biopsy techniques, including fine-needle aspiration and core needle biopsy, are replacing excisional biopsy as the treatment standard. Breast conservation therapy is now widely used in place of mastectomy, both for small tumors and for larger tumors that have been downstaged through induction chemotherapy. Less invasive procedures for axillary treatment such as lymphatic mapping and sentinel lymph-node biopsy are being explored in an effort to avoid the morbidity associated with axillary lymph-node dissection. For women who still prefer or need to receive a mastectomy, immediate breast reconstruction with autologous tissue provides an excellent cosmetic outcome that is oncologically sound. This is especially appealing to high-risk women who opt to have a prophylactic mastectomy. High-risk women are also being offered the option of receiving chemopreventive treatment that may reduce their lifetime risk of cancer by almost $50 \%$. These new, less invasive approaches require the close cooperation of a team of physicians, including surgeons, pathologists, radiologists, and medical and radiation oncologists.
\end{abstract}

Endocrine-Related Cancer (2001) 8 265-286

\section{Introduction}

For almost 100 years, the primary mode of treatment for breast cancer was radical surgery. Today, there is a climate of fundamental change in breast cancer management, as surgical treatment options evolve towards minimally invasive procedures. Importantly, the oncological soundness of these new procedures is being thoroughly demonstrated in both prospective and retrospective clinical studies.

Most tumors can now be readily diagnosed without the use of excisional biopsy. Alternative biopsy techniques, including fine-needle aspiration and core needle biopsy, do not require general anesthesia and leave minimal scarring compared with excisional biopsy. Because of the increasing use of screening mammography, most women are now initially seen with small tumors that can be removed with breast conservation therapy, preserving the breast while providing a more rapid recovery and vastly improved patient self-image. The removal of axillary lymph nodes, once a standard part of treatment, is now being questioned, and less invasive procedures for axillary sampling and treatment are being explored.
In cases in which radical surgery is still used, the direction of change has been towards procedures that are psychologically and cosmetically more acceptable to the patient. For those patients who still prefer or need to receive a mastectomy, immediate breast reconstruction provides excellent cosmetic results, especially when combined with autologous tissue flaps and skin-sparing mastectomy. These reconstruction options are especially appealing to those women who, because of a personal or family history of breast cancer, opt to have a prophylactic mastectomy. Women in this high-risk group who do not favor this aggressive surgery now have the option of receiving chemopreventive treatment with a selective estrogen receptor modulator, possibly reducing their risk of future breast cancers by almost $50 \%$.

This review will discuss six issues in the evolving field of breast cancer management: biopsy approaches; selection criteria for breast conservation therapy; minimally invasive ablation approaches for treating the primary tumor; the treatment of axillary lymph nodes; immediate breast reconstruction; and prophylactic mastectomy. Each section will provide a detailed review of recent clinical studies in the area, and close with a summary. 


\section{Biopsy approaches}

\section{General considerations}

The biopsy represents the first surgical intervention in the treatment of breast cancer. For many years, excisional biopsies were the treatment standard for most lesions. Typically, they can be comfortably performed with intravenous sedation and local anesthesia, and they provide excellent diagnostic information. Although straightforward, this type of biopsy has the potential to affect subsequent treatment, especially if it results in a large scar, or if the tumor is removed with inadequate or unknown margins. Because the majority of lesions for which women undergo biopsy prove to be benign, and because many women have multiple biopsies during their lifetimes, less invasive techniques were developed. Fine-needle aspiration (FNA) and core biopsy are both fast and simple techniques, requiring only local anesthesia. In patients with palpable tumors, these techniques can accurately diagnose the lesion in more than $90 \%$ of cases (Vega et al. 1995, Scopa et al. 1996, O’Neil et al. 1997, Pijnappel et al. 1997, Gotzinger et al. 1998). Newer techniques, including the Advanced Breast Biopsy Instrumentation (ABBI) system and several vacuum-assisted core-sampling devices (Mammatome, and Minimally Invasive Breast Biopsy (MIBB)) have been developed that may increase diagnostic accuracy by increasing the size of the tissue samples while maintaining a relatively non-invasive profile. These techniques are proving to be especially valuable when used with stereotactic or ultrasound guidance for the diagnosis of non-palpable breast tumors. A new technique involving ductal lavage may allow the retrieval of epithelial cells lining the ductal-lobular systems of the milk ducts.

\section{Advanced Breast Biopsy Instrumentation system}

The ABBI system (US Surgical Corporation, Norwalk, CT, USA) was designed as an alternative to excisional biopsy for the diagnosis of non-palpable breast tumors. Threedimensional stereotactic localization is used to guide an axial wire to the center of the tumor. A surgical cannula up to 20 $\mathrm{mm}$ in diameter is inserted down this axial guide, and used to remove tissue cylinders that encompass the tumor. Although the amount of tissue that can be removed is typically only about half as much as would be possible with a needle-directed excisional biopsy, it is significantly larger than could be obtained through core biopsy, and does not require multiple passes of the needle. It has the additional advantage over a core biopsy or FNA in potentially providing tumor margins for pathological analysis. This approach has the disadvantage of requiring a $20 \mathrm{~mm}$ initial incision for placement of the cannula. In addition, the cannula must be placed very precisely, because only a small distance (several millimeters) may separate the tumor edge and the cut surface of the tissue cylinder.

The ABBI technique is being tested in several institutions, with excellent results (Sheth et al. 1999, Portincasa et al. 2000, Schwartzberg et al. 2000). The sensitivity and specificity of ABBI biopsy for the diagnosis of carcinoma are both excellent, approaching $100 \%$ in reported studies (Matthews \& Williams 1999, Atallah et al. 2000). Positive margin and residual tumor rates are comparable to those seen with wire-localized excisional biopsy (Velanovich et al. 1999). Because it avoids operating room and re-excision costs, the technique is extremely cost-effective compared with excisional biopsy, and represents an excellent biopsy option for non-palpable breast tumors.

\section{Vacuum-assisted core biopsy instruments}

Vacuum-assisted core biopsy instruments use the same general principle as the core needle biopsy, but represent a significant advance in technology. Two systems currently in use are the Mammatome (Biopsys Medical, Cincinnati, OH, USA) and the Minimally Invasive Breast Biopsy, or MIBB (US Surgical Corporation). Both systems use a vacuum to pull tissue into a sampling chamber, where it is removed with high-speed rotating knives. The specimen is then suctioned to a chamber outside the breast, where it may be removed. These devices have the advantage of being able to obtain contiguous samples from the same area by rotating the device in a circular motion, rather than being withdrawn and reinserted, as with a standard core-biopsy needle. The probe may also be used to insert a radiopaque marker at the site to mark it for further treatment. The Mammatome uses internal oscillating knives, whereas the MIBB, which was developed later, uses an externally oscillating knife and can sample specimens up to $25 \%$ larger. The MIBB also offers two different chamber lengths $(10 \mathrm{~mm}$ and $20 \mathrm{~mm})$ and an adjustable sheath for fine-tuned variation in chamber length. The Mammatome, in contrast, has a set chamber length of $19 \mathrm{~mm}$. Vacuum-assisted core sampling devices may be especially useful in the assessment of diffuse calcifications (Liberman et al. 1997, Meyer et al. 1997)

Because some lesions are histologically heterogeneous and may simultaneously contain areas of atypical ductal hyperplasia, ductal carcinoma in situ and invasive carcinoma, the accuracy of the diagnosis from vacuum-assisted biopsy will depend to some degree on the size of the sampling needle used. Thus more accurate sampling would be anticipated from an 11-gauge needle, for example, than from a 14-gauge needle (Dershaw 2000). Overall, the reported accuracy for vacuum-assisted biopsies has approached $100 \%$, reflecting the large tissue samples available from these 
techniques (Heywang-Kobrunner et al. 1998, Simon et al. 2000).

\section{Ductal lavage}

Ductal lavage retrieves cells via a microcatheter inserted into the milk duct through the nipple surface orifices. Breast cancer is believed to start in the epithelial lining of the ductal/ lobular systems of these milk ducts. The duct is flushed with saline to wash out cells for evaluation. Although this technique is still largely experimental, preliminary studies indicate that it is safe and well tolerated, and may be useful for the early detection of intraductal breast pathology (Dooley et al. 2001).

\section{Summary}

Although still of use for large, palpable tumors, excisional biopsy has been largely replaced by less invasive techniques that offer excellent specificity and sensitivity. FNA and core biopsy are fast and cost-effective, but offer limited tissue samples. The ABBI system and techniques using vacuum-assisted core sampling devices present the advantage of greatly increased sampling ability (and the possibility of margin analysis with the ABBI system), while remaining relatively non-invasive.

\section{Selection criteria for breast conservation therapy}

One of the most significant advances in the surgical management of breast cancer has been the growing acceptance of breast conservation therapy (BCT) as the treatment of choice for many primary breast cancers. Consisting of lumpectomy and postoperative radiation treatment, BCT was originally viewed with skepticism by surgeons and patients alike. Widespread acceptance of BCT came only after large prospective trials demonstrated no differences in overall survival and disease-free survival between BCT and standard mastectomy for early breast cancer (Fisher et al. 1989c, 1995, Sarrazin et al. 1989, Veronesi et al. 1995).

The risk of locoregional recurrence for early-stage breast cancer after BCT is lifelong, ranging from 7 to $20 \%$ at extended follow-up times (Veronesi et al. 1994, Fisher et al. 1995, Jacobson et al. 1995, Arriagada et al. 1996, Van Dongen et al. 2000, Mirza et al. 2001b). Most recurrences tend to occur at the same site, and are readily salvageable by additional surgery, usually mastectomy. Various studies of salvage mastectomy after local or regional recurrence have reported 5-year disease-free survival rates ranging from 42 to $55 \%$, and overall survival rates ranging from 59 to $76 \%$ (Osborne et al. 1984, 1992, Francis et al. 1999, Voogd et al. 1999). These outcomes after locoregional recurrence following BCT are quite good, especially when compared with the grim prognosis from locoregional recurrences after mastectomy (Kurtz et al. 1989a).

The main goals of BCT are complete removal of the tumor with adequate margins, while maintaining acceptable cosmesis. Long-term outcomes are optimized by selecting patients with a reduced risk of locoregional recurrence. To attain these goals, careful attention has been paid to an extensive list of patient and tumor characteristics.

\section{Age}

Because of a variety of misconceptions, BCT has been underutilized in the elderly (Vlastos et al. 2001). Physicians may be influenced by widespread beliefs about biological differences in tumors in the elderly (e.g. they are more likely to be locally advanced, perhaps because of a decreased likelihood of having yearly screening mammograms). They may feel that the elderly, by and large, are a 'frail' population with a limited life span, best served by surgical approaches that are either palliative or at least do not require extensive post-surgical adjuvant treatment. In reality, the stages at presentation in the elderly tend to be comparable to those seen in younger women (Law et al. 1996). Because surgery for BCT is less extensive than a standard mastectomy, the perioperative morbidity and mortality should be correspondingly lower. In addition, older women tend to tolerate radiation therapy extremely well, and may also have lower rates of local recurrence after BCT than younger patients (Nemoto et al. 1991, Veronesi et al. 1995). While the presence of comorbid conditions and physiologic age should certainly be considered, old age of itself is not a contraindication for BCT.

Does younger age, then, argue against the use of BCT? Biological aggressiveness of the tumor may be greater in younger women, resulting in increased rates of local recurrence. However, rates of local recurrence and disease-specific survival do not seem to be different in younger women receiving BCT compared with younger women receiving modified radical mastectomy (Bouvet et al. $1997 a$ ). If younger patients meet other criteria for BCT, they should not be discouraged from receiving it.

\section{Family history}

Patients with a positive family history of breast cancer do not seem to have higher rates of local recurrence after BCT than patients with a negative family history (Burke et al. 1995, Chabner et al. 1998, Brekelmans et al. 1999). This may be true even for those high-risk patients who are heterozygous for mutations in the cancer-specific genes, BRCA1 and BRCA2 (Verhoog et al. 1998, Pierce et al. 2000), although a report from Memorial Sloan-Kettering found a higher in-breast rate of recurrence after BCT in 
BRCA-positive women than in controls (Robson et al. 1999). Patients with a positive family history, especially if the affected relative was premenopausal or had bilateral disease, have an increased risk for a second primary, as do BRCA1/ 2 carriers (Pierce et al. 2000). Patients should be counseled about this, but should otherwise not be discouraged from requesting $\mathrm{BCT}$.

\section{Prior history of radiation}

Patients who have had prior radiation therapy fields which included the breasts (e.g. mantle irradiation for Hodgkin's disease) are not good candidates for breast-conserving surgery with breast radiation.

\section{Pregnancy}

Although pregnancy used to be considered an absolute contraindication for $\mathrm{BCT}$, that is no longer true, with the following reservations. Pregnant women tend to have significantly more advanced disease at diagnosis than non-pregnant women, which may make them better candidates for mastectomy (Petrek et al. 1991). The surgery itself may present difficulty because of increased vascularity, and meticulous hemostasis may be required (Petrek 1994). Breast irradiation during the pregnancy is a concern. In the first trimester, a radiation dose of $5000 \mathrm{cGy}$ to the breast will expose the fetus to $10-15 \mathrm{cGy}$, and this exposure may increase to as much as $200 \mathrm{cGy}$ later in the pregnancy when the fetus is located higher in the abdomen (Van der Vange \& van Donegan 1991). Thus, although breast-conserving surgery can be carried out during pregnancy, radiation therapy should be reserved until after the completion of the pregnancy. A reasonable alternative for patients for whom chemotherapy is appropriate is to use chemotherapy during the pregnancy and reserve surgery and radiation therapy until after delivery. In the second or third trimesters, combination chemotherapy has a low risk of fetal complications (Doll et al. 1989, Weibe \& Sipila 1994), except for the use of aminopterin and other analogues of methotrexate (Doll et al. 1989).

\section{Size of the breast}

The size of the breast relative to the size of the tumor is an important issue in achieving the goals of complete removal of the tumor and maintaining adequate cosmesis. In a very small breast, complete excision of the tumor with adequate margins can result in an unacceptable deformity of the remaining breast. Bold and colleagues at the $\mathrm{M} D$ Anderson Cancer Center have overcome this difficulty by using local rotational flaps to fill in the defect left after removal of the tumor (Bold et al. 1997). They achieved excellent cosmetic results and low rates of local recurrence. A very different problem arises in women with large, pendulous breasts. In such patients, the quantity of breast tissue may make it difficult to deliver uniform doses of radiation, resulting in a higher incidence of radiation-induced side effects. This difficulty can be overcome by performing a reduction mammoplasty in the same surgery as the lumpectomy. Smith and colleagues at the M D Anderson Cancer Center have used this procedure successfully in a series of 10 patients (Smith et al. 1998). Thus neither very small nor very large breast size is an absolute exclusion factor for BCT, if the patient and her surgeon are committed to using this approach.

\section{Collagen vascular disease}

It seems likely that patients with collagen vascular diseases characterized by significant skin changes would be negatively affected by radiation. In fact, patients with systemic lupus erythematosus or scleroderma have been reported to have exaggerated side effects from radiation therapy (Fleck et al. 1989, Robertson et al. 1991). Because of the intensive regimen of radiation therapy used in BCT, such patients should be cautiously assessed as candidates for this type of treatment.

\section{Tumor size}

Patients with large tumors $(>4 \mathrm{~cm})$ have typically been excluded from consideration for BCT because of the increased likelihood of local recurrence and the possibility of unacceptable cosmesis from the surgery. Recently, however, it has been shown that locally advanced breast cancer can be downstaged with induction chemotherapy, making these patients good candidates for BCT (Singletary et al. 1992). To be considered for BCT after induction chemotherapy, the patient must show complete resolution of skin edema (peau d'orange), adequate reduction in the tumor size, no extensive intramammary lymphatic invasion, no extensive suspicious microcalcifications, and no evidence of multicentricity. In patients meeting these criteria, the local recurrence and 10-year overall survival after BCT are equivalent to those seen in early-stage breast cancer patients (Peoples et al. 1998).

\section{Tumor margins}

Because positive margins lead to increased risk for locoregional recurrence, the best rule for adequate surgery is to aim for complete clearance of invasive disease. This can extend even to microscopically involved margins, although there is currently no clear consensus about the clinical importance of this microscopic involvement. There is also no clear consensus about patients with close $(<1 \mathrm{~mm})$ margins or with focally positive margins (tumor at the margin in three or fewer low-power fields). These patients may have a 
moderately increased risk for locoregional recurrence (Gage et al. 1996). In general, re-excision may be necessary if pathology indicates positive surgical margins or if residual tumor is suggested by physical examination or mammography.

\section{Multicentricity}

Although it was originally thought that multicentric tumors were associated with particularly aggressive cancers and poor patient outcomes, this belief has not found support in clinical studies. In fact, secondary tumors arising in patients with multicentric breast cancer do not contribute significantly to outcome (Fowble et al. 1993, Hartsell et al. 1994, Vlastos et al. 2000). This is reflected in the current TNM staging system defined by the American Joint Committee of Cancer and the Union Internationale Contre le Cancer (American Joint Committee on Cancer 1997). In this system, only the size of the largest tumor is used in determining tumor stage, rather than a combination of all tumors occurring synchronously in the breast. Patients in whom tumors are found in multiple quadrants, in whom recurrence rates may be $40 \%$ or higher, are not considered appropriate for BCT. Because of the high recurrence rate, and to avoid a poor cosmetic outcome, physicians at M D Anderson Cancer Center restrict BCT to those patients in whom small multiple lesions or microcalcifications are restricted to a relatively small volume ( $<4 \mathrm{~cm}$ in diameter). Multicentric cases with an extensive intraductal component (EIC) may also be associated with a higher recurrence rate after BCT (40\%), although the study reporting this relationship examined only 10 patients with multiple lesions (Leopold et al. 1989).

\section{Tumor site}

Because of the requirement to obtain disease-free margins, tumors that are located close to or beneath the areola (including Paget's disease of the nipple) may require removal of the nipple-areolar complex. The breast mound resulting from this surgery would be similar in appearance to that seen after a reconstruction. The patient must decide whether this will be cosmetically acceptable to her.

\section{Tumor histology}

BCT has been successfully used with various histological subtypes of invasive breast cancer, with no differences in rates of local recurrence (Kurtz et al. 1989b). Two specific histologic findings, infiltrating lobular carcinoma and extensive intraductal component (EIC), have received special attention. Because of its infiltrative growth and frequent discontinuity, infiltrating lobular carcinoma can be technically difficult to remove with clear margins. Nonetheless, patients with this type of cancer who have successfully undergone BCT have locoregional recurrence and disease-specific survival rates equivalent to those associated with other histological types (Bouvet et al. 1997b). EIC has been the subject of conflicting reports but, again, if negative margins are obtained, there appear to be similar rates of recurrence in EIC-positive compared with EIC-negative tumors (Weiss et al. 1992, Gage et al. 1996). As with other tumor-related factors, the key element in both these cases is the ability to remove the primary tumor completely and with clear margins.

\section{Axillary nodal status}

Nodal positivity is not in itself an absolute contraindication for BCT, nor is the degree of nodal positivity. In a series from the Joint Center for Radiation Therapy in Boston, there were no significant differences in local recurrence rates in histologically node-negative patients compared with patients with 1-3, 4-9, or 10 or more positive nodes (Lingos et al. 1995). Because of the combined effect of radiotherapy in BCT with standard adjuvant chemotherapy, node-positive patients may actually do better with BCT than with a traditional mastectomy. Patients who are classified with Stage III cancer on the basis of the presence of fixed or matted axillary lymph nodes should undergo induction chemotherapy and be reassessed for BCT if they are clinically downstaged as a result of the therapy.

\section{Summary}

The main principles of BCT are complete removal of the tumor while maintaining adequate cosmesis. Provided these principles are maintained, there are no physical factors or combinations of factors that absolutely preclude BCT as a treatment option. The final choice of treatment, however, rests with the patient, and the patient who is a good candidate for BCT should have a strong desire to preserve her breast. She should be aware of the treatment requirements for BCT (daily radiation therapy for 5-6 weeks after surgery and indefinite follow-up), and her fears or concerns about all aspects of the treatment should be addressed.

\section{Minimally invasive ablation techniques for treating the primary tumor}

In the current climate of fundamental change in the surgical management of breast cancer, it is not surprising that interest has grown in the use of minimally invasive ablation techniques for the local treatment of tumors. Tumor ablation has been attempted with a variety of different approaches, with the goal of either cooling (e.g. cryotherapy), heating (e.g. radiofrequency ablation, focused ultrasound, laser interstitial therapy, microwave), or chemically injuring (e.g. ethanol ablation) the tumor sufficiently to induce complete 
cell death. To date, the techniques that have attracted the most interest for the treatment of breast cancer are cryotherapy and radiofrequency ablation.

\section{Cryotherapy}

Cryotherapy was originally developed and extensively used for the treatment of non-resectable metastatic disease in the liver. When used during open surgery, cryotherapy is capable of treating very large tumors. The hypoechoic iceball that is formed during cryosurgery can be monitored by intraoperative ultrasound. Cellular damage is believed to be the result of disruption of the membrane during the freeze/ thaw cycle, and can be enhanced by increasing cooling rates and by using a double freeze/thaw cycle (Rui et al. 1999). With the use of a needle through which liquid nitrogen is circulated, Rabin and colleagues have been able to cool breast tissue from $37^{\circ} \mathrm{C}$ to $-55^{\circ} \mathrm{C}$ within $15 \mathrm{~s}$ (Rabin et al. 1999a). Although cryotherapy has demonstrated usefulness for breast cancer treatment in animal models (Staren et al. 1997, Rabin et al. 1999b), the only human trial to date has involved a single patient successfully treated for two lobular carcinomas (Staren et al. 1997).

There are several areas of practical concern in the use of cryosurgery for the treatment of breast tumors. For example, ultrasound monitoring may incorrectly estimate the exact dimensions of the iceball formed during treatment (Robinson 2000). In addition, cell killing within the treatment field may not be complete. Although this may not be a critical issue in the treatment of metastatic liver cancer in which further disease is the expectation, it clearly is important in the treatment of single breast lesions that could otherwise be cured using standard therapies.

\section{Radiofrequency ablation}

Destruction of solid tumors by radiofrequency ablation (RFA) results from the frictional heat generated by intracellular ions moving in response to an alternating current. The current flows from an uninsulated electrode implanted in the tumor to a grounding pad applied externally to the skin. Hyperthermia from RFA is believed to induce cell death through effects on cell membrane fluidity, cytoskeletal proteins and nuclear structure, including disruption of DNA replication (Hamazoe et al. 1991, Haines 1994).

The physics of resistive heat generation around the electrode tip dictates a maximum size of the ablation field for a given size of the electrode. To increase the size of the ablation field, the electrode size must be effectively increased. Practically, this is done in one of two ways. Saline solution can be infused through the tip of the electrode, increasing the area of the radiofrequency current conduction (Hoey et al. 1995, Leveilee et al. 1996, Miao et al. 1997).
Alternatively, a special electrode tip can be used that contains secondary electrodes that are deployed to form a star-like array around the primary electrode. An ablation zone of $3-5 \mathrm{~cm}$ in diameter can be attained using this type of electrode.

The RFA probe is typically positioned under ultrasound guidance, and the procedure is carried out with real-time ultrasound monitoring. Ablation zones are visualized as hyperechoic areas, and treatment is stopped when the entire tumor is replaced by a hyperechoic area. When histological samples are available, tumor destruction is verified by histopathologic staining of the zone of ablation using either $\mathrm{NADH}$ diaphorase or standard hematoxylin and eosin (H\&E).

RFA has shown promise in many organ types, including liver, lung, bone, brain, kidney, pancreas and prostate gland (reviewed in Mirza et al. 2001a). Highly vascular organs such as the liver may be theoretically less vulnerable to radiofrequency energy, because the circulatory system tends to act as a heat sink, drawing heat away via conduction. Nonetheless, studies have shown an overall survival of $80-$ $90 \%$ at a median follow-up time of 8.5 months in patients with metastatic liver cancer treated with RFA.

The initial study looking at the feasibility of RFA in human breast tumors was reported in 1999 (Jeffrey et al. 1999). They treated five women with locally advanced breast cancer, with an average tumor size of 4-7 cm. Only a portion of the tumor was treated, so that the margin between ablated and non-ablated tissue could be assessed after mastectomy or lumpectomy. They found complete ablation in an area of $0.8-1.8 \mathrm{~cm}$ in four of the five patients; the fifth patient had a small area of viable cells lining a cyst. They concluded from this small study that RFA would be most effective for the treatment of tumors less than $3 \mathrm{~cm}$.

A current study at M D Anderson Cancer Center in Houston is examining the effectiveness of RFA for the treatment of invasive breast tumors $<2 \mathrm{~cm}$ in size. In most cases to date, RFA has resulted in $100 \%$ coagulative necrosis of the tumor, with no post-procedure complications related to RFA. Additional trials will be necessary to verify these results and to determine if long-term outcomes from RFA are equivalent to those seen with surgical resection of the primary tumor.

\section{Other ablation techniques}

Tumor ablation has also been attempted using ethanol injection, lasers, microwaves, and focused ultrasound. Ethanol injection has the advantage of being straightforward and minimally invasive. This approach has limited applicability, however, and works well only with highly vascular, well-encapsulated tumors, such as hepatocellular carcinomas. For other tumor types, there is the danger of uneven ethanol distribution and the risk of incomplete cell 
death. Laser interstitial therapy (LITT) causes cell death hyperthermically by means of laser energy delivered through a fiberoptic probe inserted into the tumor under imaging guidance. Much of the work in this area has involved either theoretical or animal models (Dowlatshahi et al. 1992, Robinson et al. 1996, 1998), and there are few data yet available about the effectiveness of LITT for the treatment of human breast tumors (Dowlatshahi et al. 1996). A current pilot study at the University of Arkansas for Medical Sciences has used LITT in combination with high-contrast, high-resolution magnetic resonance imaging (MRI) to treat breast lesions in 25 patients. Rigorous pathological examination after conventional breast surgery has shown complete ablation of the lesion and accurate assessment of the ablation field by MRI (S Harms, personal communication). Animal studies reported in 1999 demonstrated that microwave energy delivered as a phased array can be used to target tumors deep within the breast (Fenn et al. 1999). Ablation fields of 3-5 cm are theoretically possible, but the clinical usefulness of this approach has yet to be verified. Focused ultrasound as described by Harari and colleagues (1991) and by Hill \& ter Haar (1995) was used in a pilot study involving patients with inoperable breast tumors (Gianfelice et al. 1999), but results in this study were not verified histologically. A study currently in progress at the M D Anderson Cancer Center is using MRI-guided focused ultrasound for the treatment of early stage breast lesions $<2 \mathrm{~cm}$ in diameter.

\section{Summary}

A wide variety of ablation techniques have been proposed for the treatment of primary breast cancer, but the most promising technique for further study seems to be RFA. RFA produces effective cell killing in a predictable volume of tissue, with a low complication rate. Pilot studies in breast cancer patients have demonstrated that RFA may be useful for the local treatment of small invasive breast tumors. Other approaches have been investigated largely in animal and theoretical models, and currently seem to have no significant advantages over RFA.

\section{Evolving strategies for management of the axillary lymph nodes}

Axillary lymph node dissection (ALND) became part of the accepted management of breast cancer in the mid-1800s, and continued to be the accepted standard of care well into the 1990s. Until that time, decisions about adjunct chemotherapy were weighted heavily by nodal status. This treated paradigm has shifted significantly, as the increasing use of screening mammography has resulted in the detection of very small tumors with low probabilities of nodal involvement (Haagensen 1986, Cady et al. 1996). At the same time, large-scale prospective trials have concluded that virtually all women show a positive survival value from receiving chemotherapy, regardless of nodal status (Fisher et al. 1989a,b, Mansour et al. 1989). Thus treatment decisions are now largely made on the basis of characteristics of the primary tumor.

Because of these developments, the acceptance of ALND as standard therapy for all breast cancer patients is diminishing. This is especially true because of the significant morbidity associated with ALND; up to $60 \%$ of patients experience some degree of side effects, including lymphedema of the arm, sensory numbness, and limitation of arm motion and strength (Maunsell et al. 1993). Before abandoning ALND, however, several issues remain to be resolved, and are the subject of current intensive study.

For clinically node-positive patients, recommendations are straightforward. Most practitioners agree that ALND remains important for locoregional disease control, even if not necessary for adjuvant treatment decisions. In the case of clinically node-negative patients, however, there are additional issues. Is it ever appropriate to provide no treatment of the axilla? Is there a good alternative to ALND for the detection of occult nodal metastases? Do micrometastases $(<2 \mathrm{~mm})$ have any clinical importance? Is there a good alternative to ALND for treatment of occult or micrometastatic nodal metastases?

\section{The risk of providing no axillary treatment}

There are three groups of patients for whom the risk of nodal involvement is so low that ALND can be routinely avoided: patients with ductal carcinoma in situ (DCIS), patients with pure tubular carcinoma, and patients with microinvasive carcinoma. Nodal metastasis is seen in fewer than $1 \%$ of cases with mammographically detected DCIS or pure tubular carcinoma $<1 \mathrm{~cm}$ in diameter, and in about $3 \%$ of patients with microinvasive carcinoma (for review, see Singletary 1998).

Because the risk of nodal metastasis decreases in direct proportion to primary tumor size (Haagensen 1986), it seems reasonable to suggest that patients with small invasive tumors (T1) who are clinically node-negative might be able to avoid any treatment of the axillary lymph nodes. Unfortunately, there is an unacceptable risk in following this strategy. In a series of published reports reviewed by Singletary (1998), the incidence of nodal positivity ranged from 5 to $10 \%$ in patients with tumors $0-0.5 \mathrm{~cm}$ in size and from 10 to $20 \%$ in patients with tumors $0.6-1.0 \mathrm{~cm}$ in size. Nodal metastasis can be dealt with surgically by performing a therapeutic ALND in all but about $2 \%$ of cases (Fisher et al. 1984), and may not in any case affect long-term survival. Data from the National Surgical Adjuvant Breast and Bowel Project (NSABP) B-04 trial indicate no survival differences between patients allocated randomly to groups to undergo either total 
mastectomy or radical mastectomy (Fisher et al. 1985). (Note, however, that up to $33 \%$ of patients treated with total mastectomy alone had a limited number of lymph nodes removed as part of their surgery). Nonetheless, this outcome represents a significant psychological burden to the patients, who must endure the anxiety of anticipated recurrences and additional surgery.

\section{An alternative to ALND for the detection of occult lymph-node metastases}

Sentinel lymph-node biopsy (SLNB) has been proposed as an alternative to routine ALND for the detection of occult lymph-node metastases in patients with clinically node-negative breast cancer. SLNB is based on the observation that specific areas of the breast drain by way of efferent lymphatics to a specific lymph node (the 'sentinel' lymph node, or SLN), and then to other lymph nodes in the basin. If the SLN is negative, the remaining lymph nodes are assumed also to be negative and no ALND is necessary. If the SLN is identified as positive by intraoperative frozen section or imprint cytology, an ALND is carried out during the same surgery. If the SLN is identified as positive by more detailed histological or immunohistochemical techniques, an ALND can be carried out during a subsequent surgery.

The SLN is identified by injecting a vital dye (isosulfan blue) or a radioactive suspension (typically a technetium sulfur colloid), usually into the breast parenchyma around the tumor. Some groups have also successfully used intradermal injections into the skin over the tumor (Borgstein et al. 1997) and injections into the subareolar lymphatic plexus (Kern 1999, Klimberg et al. 1999). The tracer can then be detected visually during surgery (when the dye is used) or by using lymphoscintigraphy before surgery or a hand-held gamma ray detector during surgery (when the radioactive tag is used). In practice, the efficiency of identification of SLN by lymphoscintigraphy has typically been lower than that seen with the hand-held gamma probe, and the gamma probe is commonly used to verify the location of the SLN during surgery (De Cicco et al. 1998, Dunnwald et al. 1999). Increasingly, radioactive tracers are being monitored with a hand-held gamma probe alone.

To date, the results of SLNB have been impressive (Table 1). The SLN can be identified in more than $90 \%$ of cases; of these, the SLN accurately predicts the status of the remaining lymph nodes in more than $97 \%$ of cases. When the SLN is positive for metastatic disease, it is often the only affected node, especially in women with small primary tumors. In a study by Chu et al. (1999), women with T1/T2 tumors and SLN micrometastases $(<2 \mathrm{~mm})$ and women with T1a tumors and SLN macrometastases had a very low probability $(0-7 \%)$ of additional metastatic disease. A trial from the American College of Surgeons is currently recruiting women who are SLN-positive by routine $\mathrm{H} \& \mathrm{E}$ staining to determine if completion ALND after SLNB will affect clinical outcome in this population.

Can axillary lymph node treatment be safely eliminated in patients who are cytologically and histologically SLN-negative? Because of a significant frequency of false-negative results in SLNB, caution is urged in answering this question. False-negative rates reflect those cases in which the SLN was negative for metastasis even though there was histologically verified metastatic disease in the remaining axillary basin. In the studies represented in Table 1 , the false negative-rate ranged from 1 to $11 \%$ (median $6 \%$ ). Recent reports have associated high false-negative rates with increasing patient age, presence of medial tumors and the surgeon's limited experience with SLNB (Euhus et al.

Table 1 Results of sentinel lymph node biopsy in patients with operable breast cancer.

\begin{tabular}{|c|c|c|c|c|}
\hline Reference & $\begin{array}{l}\text { Patients in } \\
\text { whom SLN } \\
\text { identified (A) (\%) }\end{array}$ & $\begin{array}{l}\text { Patients in }(A) \text { in } \\
\text { whom SLND } \\
\text { predicted nodal } \\
\text { status (\%) }\end{array}$ & $\begin{array}{l}\text { Metastatic cases in } \\
\text { which SLN was only } \\
\text { affected node (\%) }\end{array}$ & $\begin{array}{l}\text { False negative } \\
(\%)\end{array}$ \\
\hline Borgstein et al. 1998 & $94(122 / 130)$ & $99(103 / 104)$ & $59(26 / 44)^{b}$ & 5 \\
\hline Koller et al. 1998 & $98(96 / 98)$ & $97(93 / 96)$ & $14(13 / 96)$ & 3 \\
\hline Krag et al. 1998 & $91(405 / 443)$ & $97(392 / 405)$ & $59(60 / 101)$ & 11 \\
\hline Bass et al. 1999 & $93(173 / 186)$ & $99(172 / 173)$ & NA & 1 \\
\hline Haigh et al. 2000 & $81(230 / 284)$ & $99(227 / 230)$ & $58(52 / 90)^{\mathrm{b}}$ & 3 \\
\hline Hill et al. 1999 & $93(458 / 492)$ & NA & $61(69 / 114)^{b}$ & 11 \\
\hline Kollias et al. 1999 & $81(95 / 117)$ & $98(93 / 95)$ & $42(13 / 31)$ & 7 \\
\hline Reynolds et al. 1999 & $98(220 / 225)$ & $97(177 / 182)^{\mathrm{c}}$ & $53(32 / 60)$ & NA \\
\hline Veronesi et al. 1999 & $99(371 / 376)$ & $97(359 / 371)$ & $43(73 / 168)$ & 7 \\
\hline
\end{tabular}

${ }^{a}$ False-negative rate: (number of false-negative sentinel nodes divided by number of positive axillary basins) $\times 100$.

'Metastatic nodes detected by standard H\&E staining combined with immunohistochemical staining; all other studies used H\&E staining only.

${ }^{\mathrm{C}}$ ALND performed in $182 / 225$ patients who received SLNB.

$\mathrm{NA}$, data not available. 
1999, Ng et al. 1999, Noguchi et al. 1999). To gain further information about this issue, the NSABP B-32 is currently recruiting women who are pathologically SLN-negative to compare long-term locoregional recurrence rates in women who receive SLNB alone with those in women who receive SLNB followed by standard ALND.

\section{The clinical relevance of micrometastases}

In node-negative patients with tumors $<2 \mathrm{~cm}$ (T1N0), the long-term prognosis is excellent for about $70 \%$ of patients treated with surgery of the primary tumor alone, whereas the remaining $30 \%$ will develop metastatic cancer and die within 10 years (Elledge \& McGuire 1993). It has been suggested that the at-risk patients may have micrometastatic disease in the lymph nodes (Chen et al. 1991, De Mascarel et al. 1992, Clare et al. 1997), detection of which would indicate the need for more aggressive treatment.

The growing use of SLNB has opened the door to the increased use of immunohistochemical (IHC) and molecular markers to detect micrometastases in the SLN. In published studies, the incidence of micrometastases detected by IHC in patients who were node-negative by standard H\&E staining ranged from 12 to 29\% (Trojani et al. 1987, Sedmak et al. 1989, International (Ludwig) Breast Cancer Study Group 1990, Chen et al. 1991, De Mascarel et al. 1992, Hainsworth et al. 1993, Clare et al. 1997, Kuerer et al. 1999). Do micrometastases detected by IHC have a clinical impact? Numerous retrospective studies suggest that they do, with decreases in disease-free survival ranging from 5 to $22 \%$ (Chen et al. 1991, De Mascarel et al. 1992, Clare et al. 1997). Most of these retrospective studies, however, represent macroscopic nodal disease that was missed on routine evaluation and was later confirmed by $\mathrm{H} \& \mathrm{E}$ staining. Two current prospective trials are seeking further information about the clinical importance of micrometastases detected by IHC or molecular techniques. The previously discussed American College of Surgeons trial will also examine the effect of IHC-detected micrometastases on patient outcome. A Department of Defense study is attempting to document a clinical correlation with the finding of occult metastases by RT-PCR. RT-PCR has reportedly been able to identify a neoplastic marker in a significant percentage of sentinel nodes that were negative for disease by both H\&E and IHC staining (Verblanc et al. 1999). It may be the case, however, that RT-PCR is too sensitive, identifying single cells or clusters of cells that are unlikely to become clinically important.

Regardless of the technique used to detect micrometastases (serial sectioning, IHC, or RT-PCR), isolated tumor cells and minute clusters of cells $<200 \mu \mathrm{m}$ in diameter should be considered node-negative until further information is obtained about their clinical significance.

\section{Radiation therapy as an alternative to ALND for treatment of the axilla}

Radiation therapy has been proposed as an alternative to ALND for management of the axilla in node-negative patients, especially in cases involving in situ or limited microinvasive tumors. In a series of published reports with a median follow-up time of 62 months (range 54-126 months), clinically node-negative patients who received axillary irradiation without ALND had an axillary failure rate of only about $1 \%$ (for review see Singletary 1998). In a metaanalysis, the Early Breast Cancer Trialists' Collaborative Group (1995) found no apparent difference in mortality in eight trials comparing ALND with axillary irradiation for the treatment of early breast cancer. The morbidity from axillary nodal irradiation compares favorably with the significant long-term effects seen after ALND. The risk of arm edema is reduced by at least $50 \%$ compared with ALND, and brachial plexus injury and shoulder morbidity are also substantially reduced (Pierce et al. 1992).

With induction chemotherapy, even patients with later-stage node-positive breast cancer may become candidates for radiation treatment of the axilla. In a significant number of such patients, both the primary tumor and the axilla are downstaged by induction chemotherapy, making the patients good candidates for conservative breast surgery (Peoples et al. 1998). A current clinical trial at M D Anderson Cancer Center is examining the relative effectiveness of ALND and axillary irradiation for nodal management in patients who are or who become clinically node-negative after induction chemotherapy.

\section{Summary}

For patients with clinically positive axillary lymph nodes, especially when these persist after induction chemotherapy, ALND remains the best treatment option. In clinically node-negative patients, SLNB is a useful option for detecting those patients with occult metastases who may require more aggressive treatment. Immunohistochemical and molecular techniques have allowed the identification of micrometastases not detectable by routine H\&E staining, but the clinical significance of these lesions is undetermined. For most clinically node-negative patients, including those who become node-negative as a result of induction chemotherapy, radiation of the axilla may be as effective as ALND for local control of disease.

\section{Immediate breast reconstruction}

Although breast conservation therapy has been shown to be a safe and effective treatment option for most patients with early-stage breast cancer, many women still receive 
mastectomies. For some, this is a matter of personal preference, either because of fear of recurrence in the remaining breast mound, or because of reluctance to undergo the 5-6 week radiation treatment that is recommended after lumpectomy. For others, there are medical reasons for receiving the more extensive surgery, including an unusually high risk of local recurrence or the presence of multicentric disease in more than one quadrant. For these women, it is now possible to receive immediate breast reconstruction in the same surgery as the mastectomy. If necessary, a contralateral mastopexy or reduction can also be performed to achieve symmetry between the breasts. Immediate breast reconstruction can be an important factor in recovery, contributing to a more positive body image. Current reconstructive techniques not only offer excellent cosmetic results, but also provide outcomes equivalent to standard mastectomy.

\section{Types of reconstruction}

\section{Implant reconstruction}

The oldest method of breast reconstruction involves silicone-gel or saline-filled implants. This type of reconstruction achieved great popularity in the 1960s and '70s for cosmetic breast enhancement, and initially became popular in reconstructive surgery because the artificial implants are easy and quick to insert (Fig. 1). It continues to be widely used, and can offer satisfactory cosmetic results in patients who prefer this treatment option.

There can be significant disadvantages of implant reconstruction, however. In many women, the envelope of skin where the implant will be placed needs to be expanded in a process that can take 4-6 weeks. An inflatable expander is inserted beneath the chest wall during the mastectomy, and gradually inflated with a saline solution through a subcutaneous port. Typically, another surgery replaces the expander with the implant.

There is a significant risk of medical complications from implant reconstruction, with as many as $20-30 \%$ of women experiencing infection, rupture, extrusion, or capsular contracture (Handel et al. 1995, Kraemer et al. 1996). Because of the additional treatment, including surgery, needed to deal with these complications, implant reconstruction becomes less cost-effective in the long term than the initial ease of surgery would indicate (Kroll et al. 1996). In addition, there has been widespread publicity about a possible link between silicone implants and autoimmune disease. Although the preponderance of scientific evidence does not support such a link (Committee on the Safety of Silicone Breast Implants 1999), many women continue to be wary of silicone implants, especially when a better alternative is available.

\section{Autologous reconstruction}

Autologous reconstruction uses tissue from another part of the patient's own body to reconstruct a natural-looking breast mound. The flap can remain attached to the original site with its blood supply and tunneled under the skin to the chest (a 'pedicled' flap). Alternatively, the flap can be completely removed from the donor site and attached into the mastectomy site, using microvascular techniques to attach the blood vessels in the chest to the vessels in the flap (a 'free' flap).

Although tissue from a variety of sites has been successfully used, the most widely accepted type of autologous reconstruction is a free flap using the transverse rectus abdominis muscle (TRAM) (Fig. 2). The usual TRAM flap, which includes skin, subcutaneous tissue and muscle from the lower abdomen, is large enough to reconstruct the breast (or in some cases, both breasts) without the use of additional implants. The flap's blood supply comes from the deep inferior epigastric vessels that are connected to the thoracodorsal vessels in the chest. In experienced hands, the free TRAM flap with the required microvascular surgery has a greater than $99 \%$ success rate (Schusterman et al. 1994). The use of a TRAM flap is ruled out in patients who do not have sufficient tissue to reconstruct a breast mound (i.e. those who are very thin or who have had a previous abdominoplasty, or 'tummy tuck') and in patients with extensive abdominal wall scarring from other surgeries. It is also discouraged in patients who smoke cigarettes, as there is some evidence that smoking may increase the risk of complications, including fat necrosis and partial flap loss.

A significant disadvantage of TRAM flap reconstruction is donor-site morbidity. The removal of muscle tissue from the lower abdomen can lead to complications including hernias, abdominal asymmetry, and permanent decrease in strength to flex and rotate the upper trunk. To circumvent this problem, a modification of the free TRAM flap called the deep inferior epigastric perforator (DIEP) flap has been developed (Allen \& Treece 1994, Blondeel \& Boeckx 1994, Hamdi et al. 1999). This technique involves free flaps using fat and skin alone, with dissection of the myocutaneous perforators for microvascular attachment to vessels in the chest wall. Although the initial surgery is somewhat more complex than a standard free TRAM flap, the overall cost of a DIEP flap reconstruction compares favorably with a TRAM flap, because of the improved patient recovery time and shortened duration of stay in the hospital (Kaplan \& Allan 2000). A potential disadvantage of DIEP flap reconstruction is the possibility of increased fat necrosis and flap loss as a result of the less robust blood flow than is typical with a standard TRAM reconstruction. In practice, this problem can be resolved by careful selection of patients. In a review of 310 breast reconstructions performed by a single surgeon, Kroll (2000) reported that poor outcomes could be minimized by the selection of patients who: were non-smokers; required 


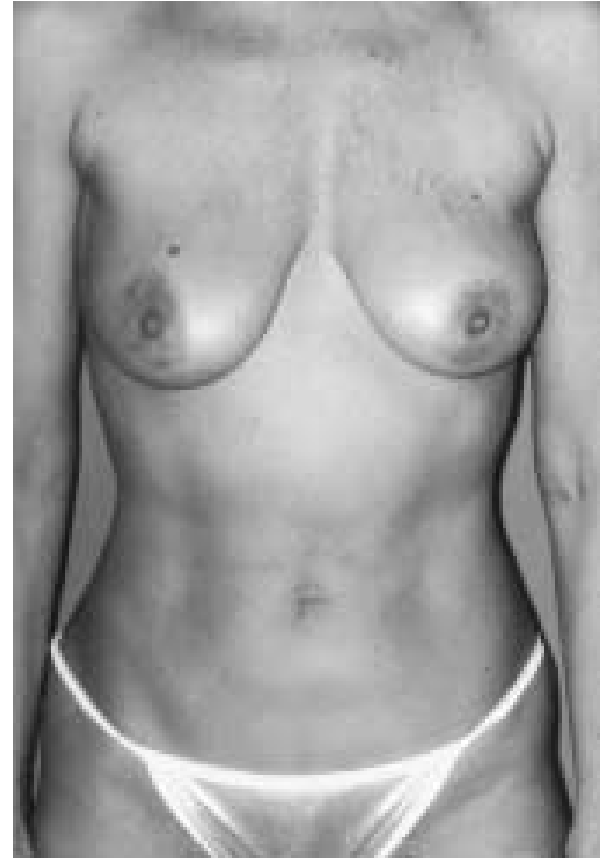

(a)

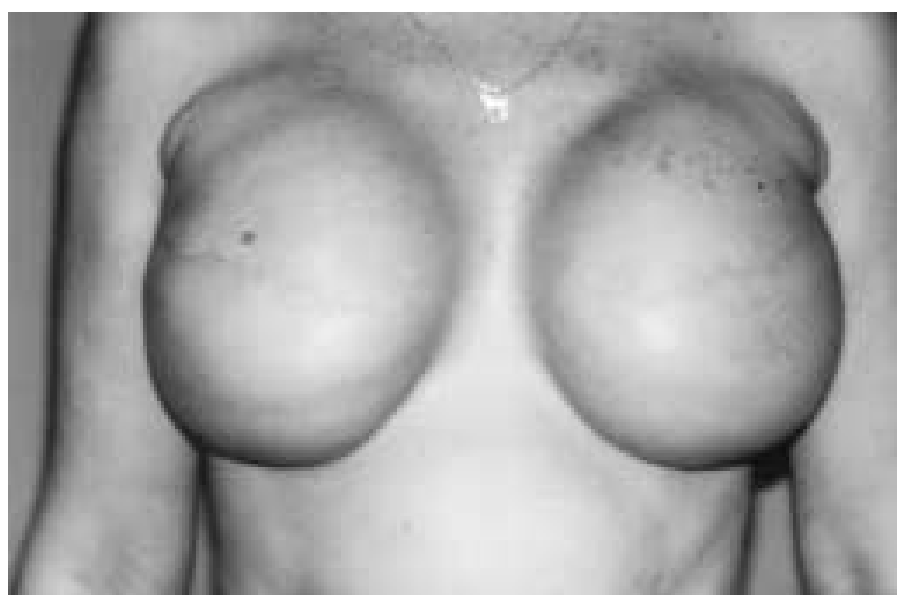

(b)

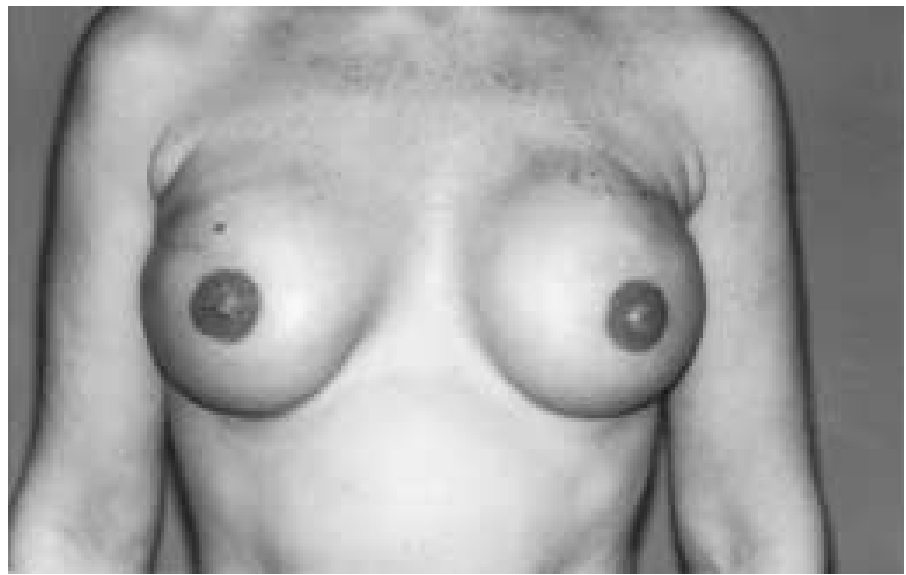

(c)

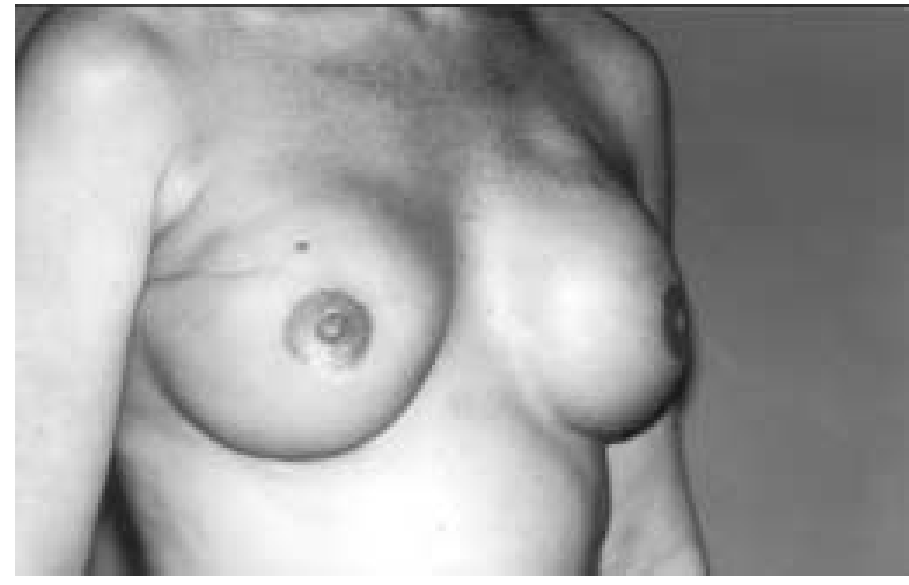

(d)

no more than $70 \%$ of the TRAM flap skin paddle to make a breast of adequate size; and had a least one perforating vessel that was $>1 \mathrm{~mm}$ in diameter with a palpable pulse. In a group of patients selected according to these criteria, rates of partial flap loss $(8.7 \%)$ and fat necrosis $(17.4 \%)$ were only
Figure 1 Bilateral breast reconstruction using tissue expanders and permanent saline implants. Elevated skin flaps and medical grade tattooing were used for nipple-areolar reconstruction. Reproduced with permission from Robb (2000). moderately greater than those seen in the free TRAM flap group (2.2\% and $12.9 \%$, respectively).

In patients in whom any kind of TRAM flap is ruled out, a latissimus dorsi flap or a gluteal free flap may be used. Both types of flap may require the addition of an artificial 


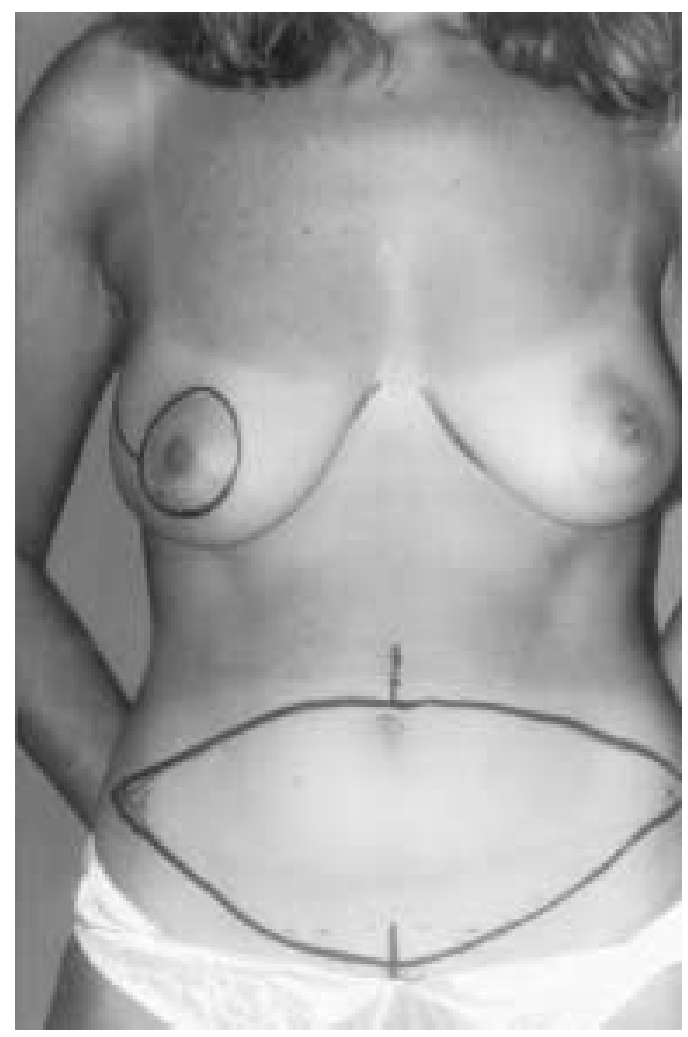

(a)

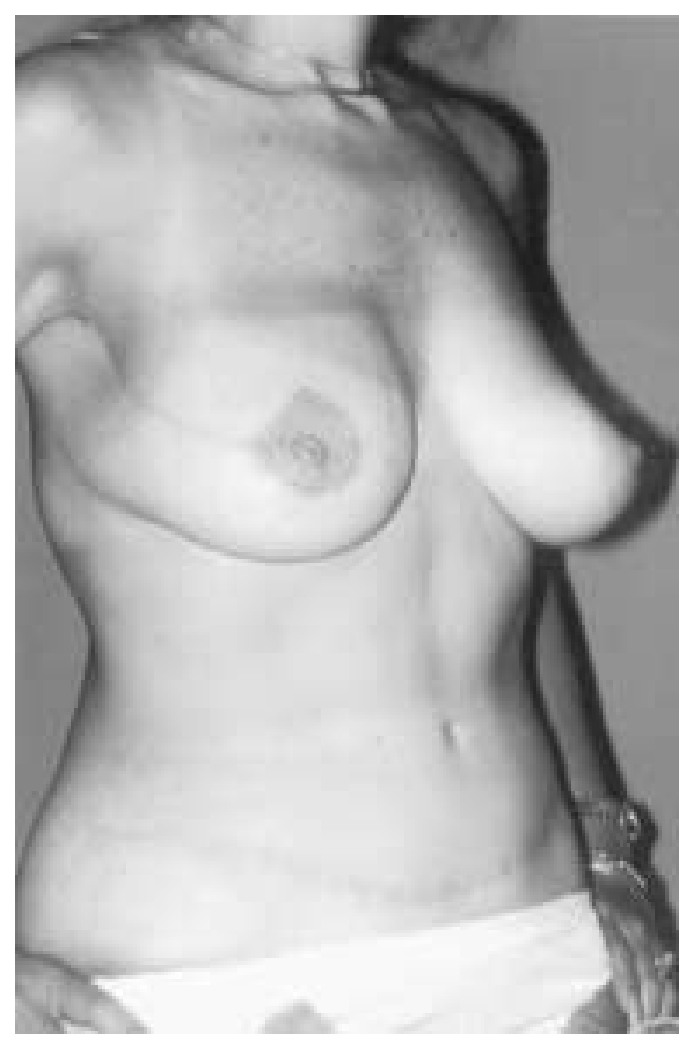

(c)

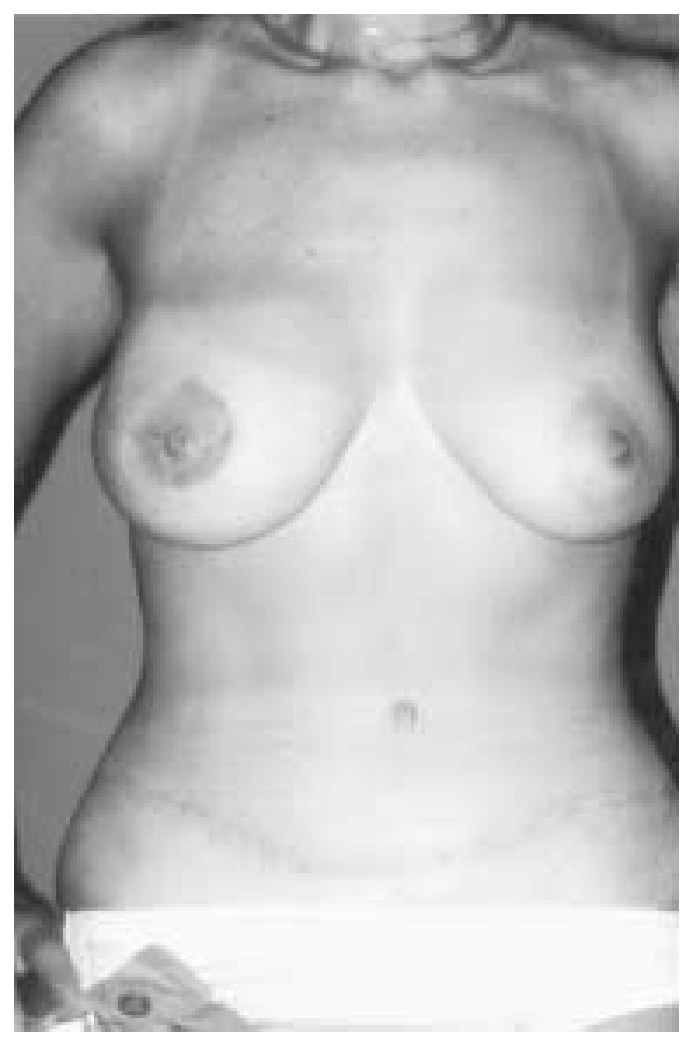

(b)

Figure 2 Immediate right breast reconstruction using a free TRAM flap after skin-sparing mastectomy. Nipple-areolar reconstruction was accomplished with elevated skin flaps and medical grade tattooing. Reproduced with permission from Robb (2000). 
implant, as removal of enough fat and skin to construct a breast mound can result in significant donor-site deformity. The gluteal free flap is technically difficult, and may require a vein graft.

In order to simulate the contralateral breast more closely, reconstruction of the nipple-areolar complex (NAC) is performed after the original surgery has healed and the edema has subsided. The nipple is usually created using small flaps of skin raised from the surrounding breast mound, and the areola is simulated using tattooing with medical-grade pigments. These procedures do not require general anesthesia.

\section{Tumor recurrence, detection and treatment}

Until fairly recently, reconstructions were delayed until all treatment of the primary tumor had been successfully completed. This was done for several reasons. It was believed that immediate reconstruction would make locoregional recurrence more likely, and that it would be more difficult to detect. It was also believed that radiation treatment could result in significant complications in the reconstructed breast.

For the most part, these earlier beliefs have not been supported by clinical data. Rates of local and locoregional recurrence in patients receiving immediate reconstruction are similar to those seen in patients receiving mastectomy only (Hortobagyi et al. 1988). Recurrences tend to appear in the mastectomy flap, where they are readily detectable by breast palpation. Radiation treatment can be used successfully after autologous tissue reconstruction, when it results in complication rates of 5-16\% (Hunt et al. 1997, Williams et al. 1997). In contrast, radiation treatment of implant-based reconstructed breasts results in an unacceptably high rate of complications. In a series of patients at M D Anderson Cancer Center, capsular contracture, pain, exposure and implant removal were reported in $41 \%$ of women receiving radiation therapy after implant reconstruction, compared with only $12 \%$ of women receiving no radiation therapy (Evans et al. 1995). While it may be possible to avoid some of the complications by covering the implant with a tissue expander, evidence supporting this remains anecdotal. Irradiation tends to cause a high rate of implant failure (43\%) even when reconstruction is carried out after irradiation (Victor et al. 1998). Overall, implant reconstruction is not recommended for women who have received or will receive radiation therapy.

\section{The use of skin-sparing mastectomy}

A major cosmetic problem involved in all types of reconstruction is constructing a breast that matches the color, size and shape of the original breast. This process is greatly facilitated by preserving as much of the patient's own skin envelope as possible in a skin-sparing mastectomy. This technique involves the removal of the breast parenchyma, axillary contents, NAC and any tumor biopsy scar. By preserving the original breast skin envelope and the inframammary fold, the plastic surgeon can reconstruct a breast that is an excellent match to the original breast. The incision is made at the border of the areola and the breast skin, and the resulting scar can be camouflaged during the reconstruction of the NAC.

This surgery is more technically demanding than a standard mastectomy, because of the importance of ensuring that the flap thickness is uniform and that a minimal volume of breast tissue remains. Carefully performed skin-sparing mastectomy results in local recurrence rates equivalent to those from a standard mastectomy (Newman et al. 1998). Recurrences typically present as easily palpable subcutaneous nodules, which can be effectively treated without resecting the entire reconstructed breast mound.

\section{Preserving the nipple}

Typically, the NAC has been included in skin-sparing mastectomies, with cosmetic reconstruction carried out during a separate surgery under local anesthesia. Although this approach has been largely successful, the use of surrounding skin flaps for reconstruction can lead to a nipple with little or no sensitivity, pale color and possible loss of projection as the scars soften over time (Spear \& Arias 1995, Tanabe et al. 1997, Lossing et al. 1998). Retention of the original NAC would be desirable, but this practice has been avoided because of the belief that there might be a high frequency of occult tumors in this area. However, NAC resection may not be medically necessary in selected patients. In a recent retrospective study at the M D Anderson Cancer Center, Laronga and colleagues (1999) reported that NAC involvement occurs in only about $3 \%$ of patients undergoing skin-sparing mastectomies, if patients with multicentric or subareolar primary tumors are excluded. Women who are clinically node-negative and who have small, solitary tumors on the periphery of the breast are at especially low risk, and would be good candidates for NAC preservation (Fig. 3).

\section{Summary}

Immediate breast reconstruction is a valuable treatment option for those women who prefer or need to have a mastectomy. Especially when combined with skin-sparing mastectomy and the use of autologous tissue, it offers a superior cosmetic result without compromising outcome. Newly developed modifications, including the use of DIEP flap reconstruction and NAC preservation, continue to challenge long-held beliefs about the medical feasibility of reconstructive techniques. Implant reconstruction continues 


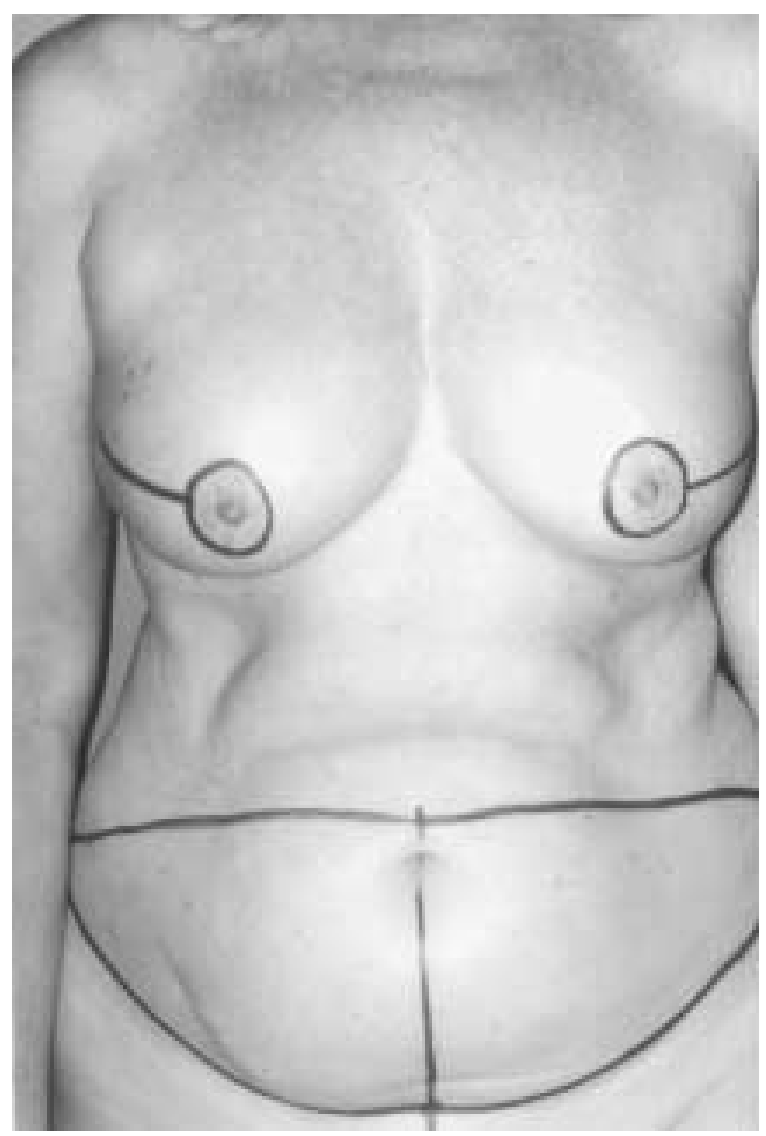

(a)

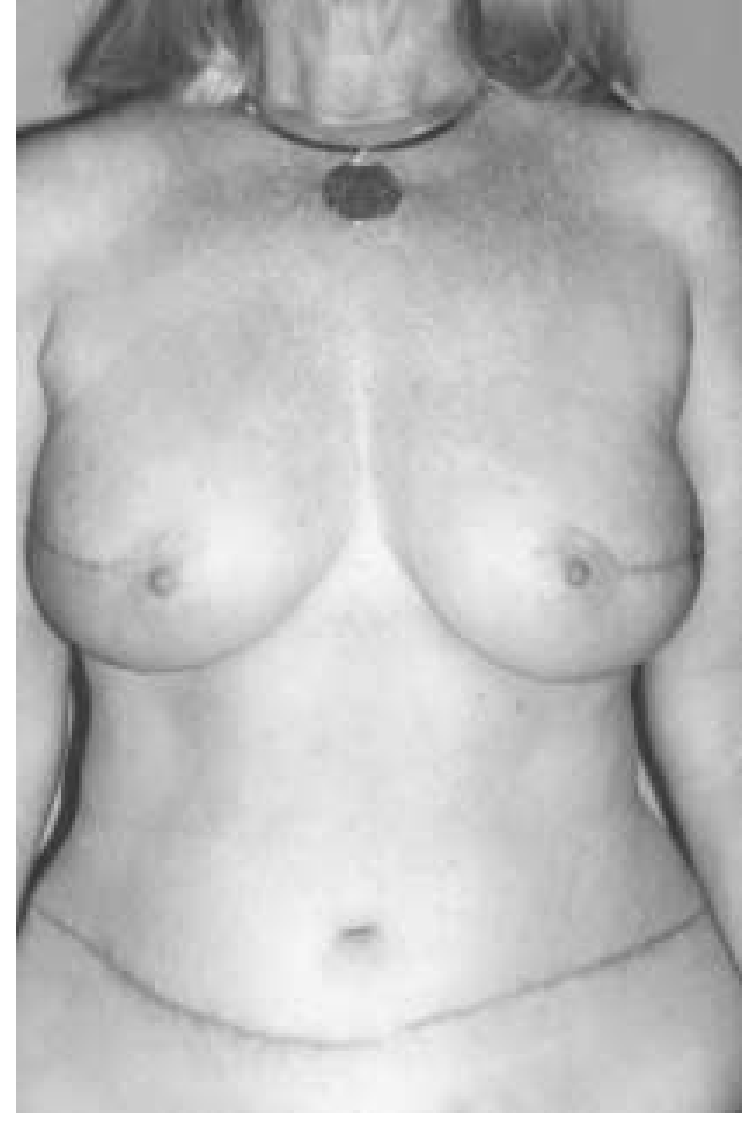

(b)

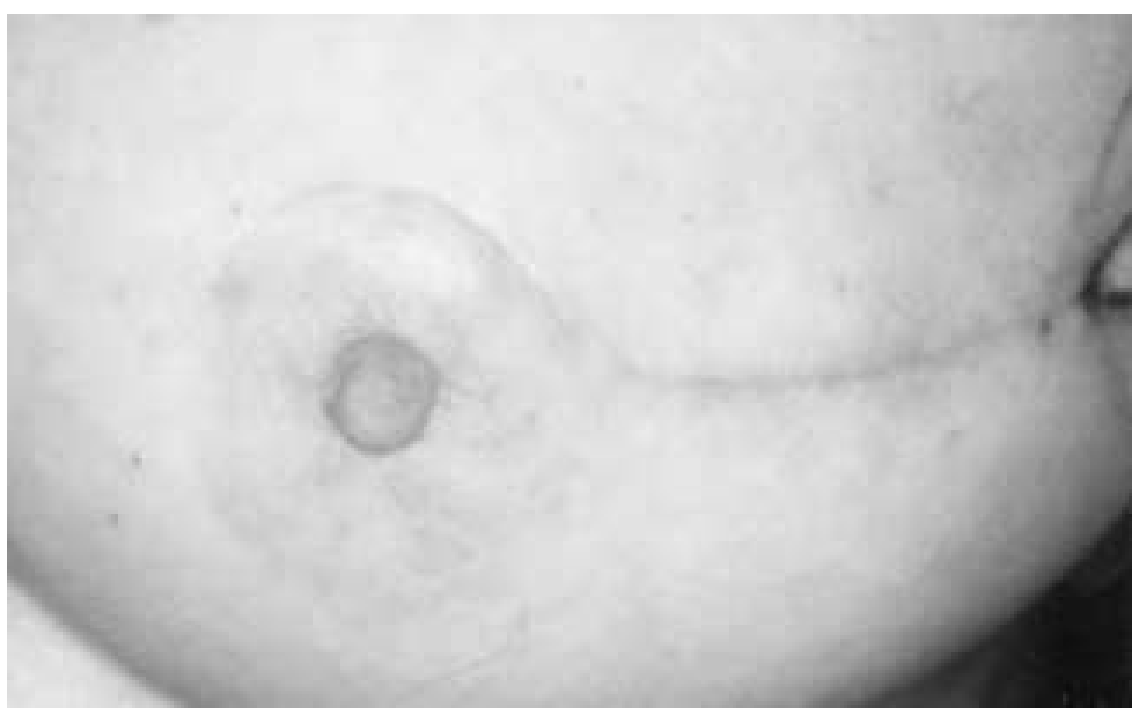

(c)

Figure 3 Bilateral mastectomy with oncologically safe preservation of the nipple-areolar complexes on the mastectomy flaps. Immediate breast reconstruction was carried out using free TRAM flaps. Reproduced with permission from Laronga et al. (1998). 
to be a useful treatment option for some women. This would include patients with significant comorbidity or those who might otherwise prefer to avoid the more rigorous surgery, in addition to women who have received previous abdominal surgery, those who are very thin, or those who are heavy smokers.

\section{Prophylactic mastectomy}

It is now possible to identify women who may be at increased risk for developing breast cancer. Some women are carriers of specific gene mutations that predispose to breast cancer, including $B R C A 1, B R C A 2, \quad p 53$, and ataxia telangiectasia. Women who test positive for $B R C A$ gene mutations, for example, have a 36-85\% increased lifetime risk of breast cancer (Fodor et al. 1998, Vasen et al. 1998, Curry \& Fentimen 1999). Women with a family history of breast or ovarian cancer in first-degree relatives are at increased risk, whether or not they are found to carry specific breast-cancer-related genes. Women with a personal history of breast cancer are also at increased risk for development of cancer in the contralateral breast, again, regardless of whether or not they are found to carry specific breast-cancer genes. The presence of certain non-cancerous or potentially pre-cancerous breast conditions, such as atypical hyperplasia (ductal or lobular) or lobular carcinoma in situ increases the lifetime risk of subsequent development of breast cancer. For example, lobular carcinoma in situ is associated with a 10$15 \%$ increase in lifetime risk of cancer in each breast, although in itself it is not considered to be a precursor of cancer (Wheeler et al. 1974, Anderson 1977).

The two principal management options for women at increased risk for the development of breast cancer are prophylactic mastectomy and intensive screening with or without chemoprevention. Each of these approaches has advantages and disadvantages. With the current lack of prospective data examining their relative benefits, a treatment choice will be largely related to how aggressively a woman wants to deal with her increased risk of cancer development.

\section{Prophylactic mastectomy}

Prophylactic mastectomy can be performed using two technically different mastectomy procedures. In a subcutaneous mastectomy, the entire underlying mass of breast tissue is removed, but the overlying skin (including the NAC) is spared, as are the axillary contents. In a total mastectomy, the entire breast and nipple-areolar complex are resected, but the axillary contents are spared. With both of these procedures, it is possible that some breast tissue can be left behind. Subcutaneous mastectomy has been particularly criticized because of the possibility of leaving tissue at the undersurface of the NAC. Although most large-scale studies have reported successful results from subcutaneous mastectomy (Pennisi \& Capozzi 1989, Hartmann et al. 1999), total mastectomy is considered to be the more definitive procedure.

Prophylactic mastectomy can greatly reduce the risk of breast cancer while achieving an excellent cosmetic outcome. Hartmann et al. (1999) examined outcomes in 639 women with a positive family history who received bilateral prophylactic mastectomy. At a median follow-up of 14 years, the incidence of new breast cancers was only $1.1 \%$, representing a $91 \%$ reduction in risk when compared with female siblings who had not undergone prophylactic mastectomy. Similarly, Ziegler \& Kroll (1991), re-analyzing data originally reported by Pennisi \& Capozzi (1989), found an incidence of $1.2 \%$ in 510 high-risk patients who had undergone prophylactic mastectomy.

The continuing refinement of immediate breast reconstruction techniques with autologous tissue now offers excellent cosmetic results from a surgery that once would have been massively deforming. The use of TRAM flaps is currently favored by physicians practised in the technique, and offers sufficient tissue and coverage to reconstruct both breasts, if both are reconstructed during the same surgery. Should a woman opt for a TRAM flap reconstruction of one breast and later develop a contralateral breast cancer, it is not technically feasible to perform a second TRAM reconstruction. Because of this, and because surgery is often necessary on the unaffected breast to obtain cosmetic matching, prophylactic mastectomy may be suggested for the high-risk patient.

An important disadvantage of prophylactic mastectomy is that, because not all of the breast tissue can be removed, breast cancer remains a possibility. Some tissue can remain on the skin flaps, in the axilla, or at the inframammary fold. In animal studies in which rats and mice received prophylactic mastectomies, both spontaneous and chemically induced tumors continued to develop (Wong et al. 1986, Nelson et al. 1989). In humans, although prophylactic mastectomy greatly reduces the incidence of new cancers, it does not eliminate them completely; primary breast cancer has been reported after prophylactic mastectomy (Ziegler \& Kroll 1963).

Other disadvantages of prophylactic mastectomy concern residual effects of the surgery and patients' perceptions of the outcomes. A study by Payne and colleagues at Memorial Sloan Kettering (2000) found that 21 of 370 women who had received a bilateral prophylactic mastectomy expressed regrets over the procedure. The most common regret involved psychological distress and the unavailability of appropriate support systems to deal with this during the process. There were also concerns expressed about the surgical outcome (complications, residual pain) and concerns related to the cosmetic results (concerns about body image, sexual dysfunction). Overall, there was a perceived lack of 
Table 2 Society of Surgical Oncology (1993) position statement on candidates for consideration for prophylactic mastectomy.

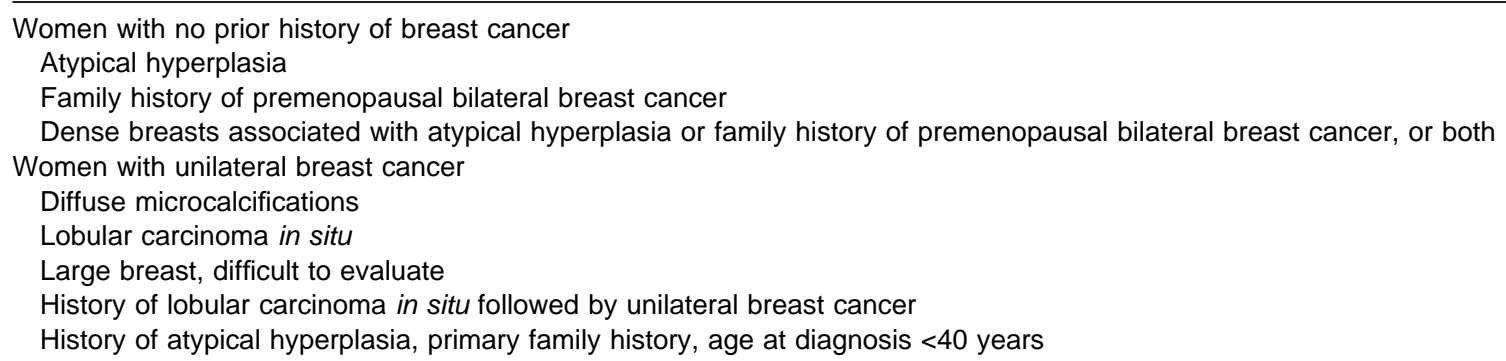

education about what to expect, both physically and psychologically.

Nonetheless, most patients were satisfied with the procedure. In the study by Payne et al. (2000) and in a similar study by Frost and colleagues (2000), the majority of patients reported favorable psychological and social outcomes, along with a diminished level of concern about developing breast cancer. For patients who are at high risk, especially those who are extremely anxious about the possibility of future cancers, prophylactic mastectomy is a useful treatment option. A list of clinical conditions warranting prophylactic mastectomy has been developed in a position statement by the Society of Surgical Oncology (1993; Table 2). In addition to the conditions listed, general guidelines in use at M D Anderson Cancer Center suggest prophylactic mastectomy as an appropriate therapy in cases of asymmetry of the contralateral breast in patients undergoing or having undergone a mastectomy who desire breast reconstruction, or in cases of psychological disability as a result of extreme fear of breast cancer.

It is important to remember, however, that there are no absolute indications for prophylactic mastectomy. Even with the overall favorable results from the procedure, it remains a highly aggressive therapy and may be contraindicated, even in patients who are candidates, by one or more of the above-mentioned criteria. Patients with a poor prognosis from the primary breast tumor are not good candidates, neither are patients with an overall poor prognosis from comorbid conditions. Even if the procedure is not contraindicated, most women simply do not want a prophylactic mastectomy - even those who are high-risk carriers of BRCA gene mutations (Lerman et al. 2000, Meiser et al. 2000). For these women, a second option is intensive screening, especially when combined with newly available approaches to chemoprevention.

\section{Screening and chemoprevention}

Heightened surveillance, with screening mammography, clinical evaluation, and breast self-examination of the breast, continue to offer a safe alternative for many high-risk women. Considering that a significant percentage of all
$B R C A$ gene mutation carriers will never get breast cancer, many women may choose this option, depending upon their level of comfort with the relatively high risk. Unfortunately, many high-risk women do not adhere to surveillance recommendations (Lerman et al. 2000). In addition, intensive surveillance may not be optimally effective in detecting early-stage carcinoma in young women with BRCA mutations. Tumors in this group, when they do appear, are likely to be fast growing in addition to being difficult to detect in the dense breast tissue that is common in this age group. Thus, for selected patients, chemoprevention may be an important adjunct to surveillance.

The National Surgical Adjuvant Breast and Bowel Project P-1 trial found that a dose of tamoxifen $20 \mathrm{mg} /$ day taken for 5 years resulted in a $49 \%$ reduction in the incidence of new invasive breast cancers in women at increased risk for breast cancer (Fisher et al. 1998). Although this study did not specifically address the BRCA-carrier status of the women, it did show a significant reduction in breast cancer risk in those with first-degree relatives with breast cancer, which would certainly include those likely to have a gene for genetic susceptibility. This highly significant result means that chemoprevention may be a good option for high-risk women who are unwilling to undergo a prophylactic mastectomy. The disadvantage of long-term tamoxifen treatment includes an increased risk of endometrial cancer and thromboembolitic phenomena, and an increase in symptoms such as hot flushes, cold sweats and vaginal discharge. In the Study of Tamoxifen and Raloxifene trial, the selective estrogen receptor modulator raloxifene is currently being tested to determine if it is as effective as tamoxifen in reducing the incidence of cancer, possibly with fewer undesirable side effects (Fisher 1999). For both tamoxifen and raloxifene, chemoprevention effects are seen in a reduced risk for the development of estrogenreceptor-positive tumors only.

\section{Summary}

Women who are at high risk for the development of breast cancer may choose to have prophylactic mastectomy followed by immediate reconstruction. For women who are 
not good candidates for this aggressive surgery, or who choose not to have it, heightened surveillance is a safe option, especially when combined with chemoprevention.

\section{Conclusions}

For many years after the pioneering work of Halsted in the 1880s (Halsted 1894), the surgeon was the primary architect of breast cancer treatment, and mastectomy was the chief tool. During the past 30 years, however, this picture has changed dramatically. In a climate of growing acceptance of less invasive surgical approaches, breast cancer management now involves a team of physicians, including surgeons, pathologists, radiologists, and medical and radiation oncologists. These teams are able to bring the latest research in many different disciplines to bear on the problem of increasing overall and disease-free survival, while simultaneously decreasing surgical invasiveness and cosmetic impact. The ultimate goal of this evolving treatment paradigm will be the increasing use of systemic therapy as the main component of cancer therapy, with minimally invasive surgery to remove any residual tumor that remains after the completion of the primary therapy. The development of custom-designed genetic and biological treatment modalities is still in its infancy, but the possibility of systemic treatment specifically tailored for the individual will continue to fuel the push for less invasive surgical approaches.

\section{References}

Allen RJ \& Treece P 1994 Deep inferior epigastric perforator flap for breast reconstruction. Annals of Plastic Surgery 32 32-38.

American Joint Committee on Cancer 1997 Breast. In AJCC Cancer Staging Manual, 5th edn, pp 171-180. Philadelphia: Lippincott-Raven.

Anderson JA 1974 Invasive breast carcinoma with lobular involvement. Frequency and location of lobular carcinoma in situ. 1974 Acta Pathologica et Microbiologica Scandinavica [A] 82 719-729.

Arriagada R, Le MG, Rochard F \& Contesso G 1996 Conservative treatment versus mastectomy in early breast cancer: patterns of failure with 15 years of follow-up data. Institut Gustave-Roussy Breast Cancer Group. Journal of Clinical Oncology 14 15581564.

Atallah N, Karam R, Younane T \& Aftimos G 2000 Stereotaxic excisional biopsy of non-palpable breast lesions by the ABBI (Advanced Breast Biopsy Instrumentation) technique. Journal Medical Libanais 48 70-76.

Bass SS, Dauway E, Mahatme A, Ku NN, Berman C, Reintgen D \& Cox CE 1999 Lymphatic mapping with sentinel lymph node biopsy in patients with breast cancers $<1$ centimeter (T1a-T1b). American Surgeon 65 857-861.

Blondeel PN \& Boeckx WD 1994 Refinements in free flap breast reconstruction: the free bilateral deep inferior epigastric perforator flap anastomosed to the internal mammary artery. British Journal of Plastic Surgery 47 495-501.
Bold RJ, Kroll SS, Baldwin BJ, Rose MI \& Singletary SE 1997 Local rotational flaps for breast-conservation treatment as an alternative to mastectomy. Annals of Surgical Oncology 4 540544.

Borgstein PJ, Meijer S \& Pijpers R 1997 Intradermal blue dye to identify sentinel lymph node in breast cancer. Lancet 3491668 1669.

Borgstein PJ, Pijpers R, Comans EF, Van Diest PJ, Boom RP \& Meijer S 1998 Sentinel lymph node biopsy in breast cancer: guidelines and pitfalls of lymphoscintigraphy and gamma probe detection. Journal of the American College of Surgeons $\mathbf{1 8 6}$ 275-283.

Bouvet M, Babiera GV, Tucker SL, McNeese M \& Singletary SE $1997 a$ Does breast conservation therapy in young women with breast cancer adversely affect local disease control and survival rate? The M D Anderson Cancer Center Experience. Breast Journal 3 169-175.

Bouvet M, Ollila DW, Hunt KK, Babiera GV, Spitz FR, Giuliano AE, Strom EA, Ames FC, Ross MI \& Singletary SE 1997b Role of conservation therapy for invasive lobular carcinoma of the breast. Annals of Surgical Oncology 4 650-654.

Brekelmans CT, Voogd AC, Botke G, van Geel BN, Rodrigus P, Rutgers EJ, Klijn JG \& Coebergh JW 1999 Family history of breast cancer and local recurrence after breast conserving therapy. The Dutch Study Group on Local Recurrence after Breast Conservation. European Journal of Cancer 35 620-626.

Burke M-F, Allison R \& Tripcony L 1995 Conservative therapy of breast cancer in Queensland. International Journal of Radiation Oncology, Biology, Physics 31 295-303.

Cady B, Stone MD, Schuler JG, Thakur R, Wanner MA \& Lavin PT 1996 The new era in breast cancer: invasion, size, and nodal involvement dramatically decreasing as a result of mammographic screening. Archives of Surgery 131 301-308.

Chabner E, Nixon A, Gelman R, Hetelekedis S, Recht A, Bornstein B, Connolly J, Schnitt S, Silver B, Manola J, Harris J \& Garber J 1998 Family history and treatment outcome in young women after breast-conserving surgery and radiation therapy for early-stage breast cancer. Journal of Clinical Oncology 16 1045-1051.

Chen ZL, Wen DR, Coulson WF, Giuliano AE \& Cochran AJ 1991 Occult metastases in the axillary lymph nodes of patients with breast cancer node negative by clinical and histologic examination and conventional histology. Disease Markers 9 239-248.

Chu KU, Turner RR, Hansen NM, Brennan MB, Belchik A \& Giuliano AE 1999 Do all patients with sentinel node metastasis from breast carcinoma need complete axillary node dissection? Annals of Surgery 229 536-541.

Clare SE, Sener SF, Wilkens W, Goldschmidt R, Merkel D \& Winchester DJ 1997 Prognostic significance of occult lymph node metastases in node-negative breast cancer. Annals of Surgical Oncology 4 447-451.

Committee on the Safety of Silicone Breast Implants 1999 Safety of Silicone Breast Implants. Washington, DC: Institute of Medicine.

Curry P \& Fentimen IS 1999 Management of women with a family history of breast cancer. International Journal of Clinical Practice 3 192-196.

De Cicco C, Cremonesi M, Luini A, Bartolomei M, Grana C, Prisco G, Galimberti V, Calza P, Viale G, Veronesi U \& Paganelli G 1998 Lymphoscintigraphy and radioguided biopsy 
of the sentinel axillary node in breast cancer. Journal of Nuclear Medicine 39 2080-2084.

De Mascarel I, Bonichon F, Coindre JM \& Trojani M 1992 Prognostic significance of breast cancer axillary lymph node micrometastases assessed by two special techniques: reevaluation with longer follow-up. British Journal of Cancer 66 523-527.

Dershaw DD 2000 Stereotactic breast biopsy. In Advanced Therapy of Breast Disease, pp 89-98. Eds SE Singletary \& GF Robb. Hamilton: BC Decker Inc.

Doll DC, Ringenberg S \& Yarbro JW 1989 Antineoplastic agents and pregnancy. Seminars in Oncology 16 337-346.

van Dongen JA, Voogd AC, Fentiman IS, Legrand C, Sylvester RJ, Tong D, vander Schueren E, Helle PA, van Zijl K \& Bartelink H 2000 Long-term results of a randomized trial comparing breast-conserving therapy with mastectomy: European Organization for Research and Treatment of Cancer 10801 trial. Journal of the National Cancer Institute 92 1143-1150.

Dooley WC, Veronesi U, Elledge R, O’Shaughnessy J, Ljung B \& Arias R 2001 Detection of premalignant and malignant breast cells by ductal lavage. Obstetrics and Gynecology 97 (Suppl 1) S2.

Dowlatshahi K, Babich D, Bangert J \& Kluiber R 1992 Histologic evaluation of rat mammary tumor necrosis by interstitial Nd:YAG laser hyperthermia. Lasers in Surgery and Medicine 12 159-164.

Dowlatshahi K, Fon M, Shekarklau BA, Bloom KJ \& Gould VE 1996 Stereotactic interstitial laser therapy for early-stage breast cancer. Breast Journal 2 304-311.

Dunnwald LK, Mankoff DA, Byrd DR, Anderson BO, Moe RE, Yeung RS \& Early JR 1999 Technical aspects of sentinel node lymphoscintigraphy for breast cancer. Journal of Nuclear Medicine and Technology 27 106-111.

Early Breast Cancer Trialists' Collaborative Group 1995 Effects of radiotherapy and surgery in early breast cancer. New England Journal of Medicine 333 1444-1455.

Elledge RM \& McGuire WL 1993 Prognostic factors and therapeutic decisions in axillary node-negative breast cancer. Annual Review of Medicine 44 201-220.

Euhus DM, Peters GN, Leitch AM, Saboorian H, Matthews D, Erdman S \& Huth J 1999 Validating the performance of the mammary sentinel node team. Breast Cancer Research and Treatment 5736 (Abstract 107).

Evans GR, Schusterman MA, Kroll SS, Miller MJ, Reece GP, Robb GL \& Ainslie N 1995 Reconstruction and the radiated breast: is there a role for implants? Plastic and Reconstructive Surgery 96 1111-1115.

Fenn AJ, Wolf GL \& Fogle RM 1999 An adaptive microwave phased array for targeted heating of deep tumors in intact breast: animal study results. International Journal of Hyperthermia 15 45-61.

Fisher B 1999 Highlights from recent National Surgical Adjuvant Breast and Bowel Project studies in the treatment and prevention of breast cancer. Cancer Journal for Clinicians 49 159-177.

Fisher ER, Sass R \& Fisher B 1984 Pathologic findings from the National Surgical Adjuvant Project for Breast Cancers (protocol No. 4). X Discriminants for tenth year treatment failure. Cancer 53 712-723.

Fisher B, Redmond C, Fisher ER, Bauer M, Wolmark N, Wickerham DL, Deutsch M, Montague E, Margolese R \& Foster R 1985 Ten-year results of a randomized clinical trial comparing radical mastectomy and total mastectomy with or without radiation. New England Journal of Medicine 312 674-681.
Fisher B, Costantino J, Redmond C, Poisson R, Bowan D, Couture J, Dimitrov N, Wolmark N, Wickerham DL \& Fisher ER $1989 a$ A randomized clinical trial evaluating tamoxifen in the treatment of patients with node-negative breast cancer who have estrogen-receptor positive tumors. New England Journal of Medicine 320 479-484.

Fisher B, Redmond D, Dimintrov NV, Bowman C, Legault-Poisson S, Wickerham DL, Wolmark N, Fisher ER, Margolese R \& Sutherland C 1989b A randomized clinical trial evaluating sequential methotrexate and fluorouracil in the treatment of patients with node negative breast cancer who have estrogen-receptor negative tumors. New England Journal of Medicine 1989320 473-478.

Fisher B, Redmond C, Poisson R, Margolese R, Wolmark N, Wickerham L, Fisher E, Deutsch M, Coplan R \& Pilcor Y $1989 c$ Eight-year results of a randomized clinical trial comparing total mastectomy and lumpectomy with or without irradiation in the treatment of breast cancer. New England Journal of Medicine 320 822-828.

Fisher B, Anderson S, Redmond CK, Wolmark N, Wickerham DL \& Cronin WM 1995 Reanalysis and results after 12 years of follow-up in a randomized clinical trial comparing total mastectomy with lumpectomy with or without irradiation in the treatment of breast cancer. New England Journal of Medicine 333 1456-1461.

Fisher B, Costantino JP, Wickerham DL, Redmond CK, Kavanah M, Cronin WM, Vogel V, Robidoux A, Dimitrov N, Atkins J, Daly M, Wieand S, Tan-Chiu E, Ford L \& Wolmark N 1998 Tamoxifen for prevention of breast cancer: report of the National Surgical Adjuvant Breast and Bowel Project P-1 Study. Journal of the National Cancer Institute 90 1371-1388.

Fleck R, McNeese MD, Ellerbroek NA, Hunter TA \& Holmes FA 1989 Consequences of breast irradiation in patients with pre-existing collagen vascular disease. International Journal of Radiation Oncology, Biology, Physics 17 829-833.

Fodor FH, Weston A, Bleiweiss IJ, McCurdy LD, Walsh MM, Tartter PI, Browser ST \& Eng CM 1998 Frequency and carrier risk associated with common BRCA1 and BRCA2 mutations in Ashkenazi Jewish breast cancer patients. American Journal of Human Genetics 63 45-51.

Fowble B, Yeh I-T, Schultz DJ, Solin LJ, Rosato EF, Jardines L, Hoffman J, Eisenberg B, Weiss MC \& Hanks G 1993 The role of mastectomy in patients with stage I-II breast cancer presenting with gross multifocal or multicentric disease or diffuse microcalcifications. International Journal of Radiation Oncology, Biology, Physics 27 567-573.

Francis M, Cakir B, Ung O, Gebski V \& Boyages J 1999 Prognosis after breast recurrence following conservative surgery and radiotherapy in patients with node-negative breast cancer. British Journal of Surgery 86 1556-1562.

Frost MH, Schaid DJ, Sellers TA, Slezak JM, Arnold PG, Woods JE, Petty PM, Johnson JL, Sitta DL, McDonnell SK, Rummans TA, Jenkins RB, Sloan JA \& Hartmann LC 2000 Long-term satisfaction and psychological and social function following bilateral prophylactic mastectomy. Journal of the American Medical Association 284 319-324.

Gage I, Schnitt SJ, Nixon AJ, Siever B, Recht A, Troyan SL, Eberlein T, Love SM, Gelman R, Harris JR \& Connolly JL 1996 Pathologic margin involvement and the risk of recurrence in patients treated with breast-conserving therapy. Cancer 78 19211928. 
Gianfelice DC, Mallovche H \& Lepanto L 1999 MR-guided focused ultrasound ablation of primary breast neoplasms (works in progress). RSNA Scientific Program: Breast Intervention, Chicago, 28 November 1999. Abstract 25.

Gotzinger P, Gebhard B, Gnant M, Rudas M, Reiner A \& Jakesz R 1998 Value of punch biopsy in diagnosis of palpable breast tumors. A prospective analysis of 150 patients. Chirurg 69 $1068-1071$.

Haagensen C 1986 Diseases of the Breast. Philadelphia: WB Saunders.

Haigh PI, Hansen NM, Qi K \& Giuliano AE 2000 Biopsy method and excision volume do not affect success rate of subsequent sentinel lymph node dissection in breast cancer. Annals of Surgical Oncology 7 21-27.

Haines DE 1994 The pathophysiology of radiofrequency lesion formation. In Catheter Ablation of Arrhythmias, pp105-127. Ed. DP Zipes. Armonk: Futura Publishing Co., Inc.

Hainsworth PJ, Tjandra JJ, Stillwell RG, Machet D, Henderson MA, Rennic GC, Mckenzie IF \& Bennett RC 1993 Detection and significance of occult metastases in node-negative breast cancer. British Journal of Surgery 80 459-463.

Halsted WS 1894 The results of operations for the cure of cancer of the breast performed at the Johns Hopkins Hospital from June, 1889 to January, 1894. Johns Hopkins Hospital Bulletin 4 297-321.

Hamazoe R, Maeta M, Murakami A, Yamashiro J \& Kaibara N 1991 Heating efficiency of radiofrequency capacitative hyperthermia for treatment of deep-seated tumors in the peritoneal cavity. Journal of Surgical Oncology 48 176-179.

Hamdi M, Weiler-Mithoff EM \& Webster MHC 1999 Deep inferior epigastric perforator flap in breast reconstruction: experience with the first 50 flaps. Plastic and Reconstructive Surgery 103 86-95.

Handel N, Jensen JA, Black Q, Waisman JR \& Silverstein MJ 1995 The fate of breast implants: a critical analysis of complications and outcomes. Plastic and Reconstructive Surgery 96 1521-1533.

Harari PM, Hynynen KH, Roemer RB, Anhalt DP, Schimm DS, Stea B \& Cassady JR 1991 Development of scanned focused ultrasound hyperthermia: clinical response evaluation. International Journal of Radiation Oncology, Biology, Physics 21 831-840.

Hartmann LC, Schaid DJ, Woods JE, Crotty TP, Myers JL, Arnold PG, Petty PM, Sellers TA, Johnson JL, McDonnell SK, Frost MH \& Jenkins RB 1999 Efficacy of bilateral prophylactic mastectomy in women with a family history of breast cancer. New England Journal of Medicine 340 77-84.

Hartsell WF, Recine DC, Griem KL \& Cobleigh MA 1994 Should multicentric disease be an absolute contraindication to the use of breast-conserving therapy? International Journal of Radiation Oncology, Biology, Physics 30 49-53.

Heywang-Kobrunner SH, Smolny T, Schaumloffel U, Heinig A, Buchmann J \& Lampe D 1998 New methods for minimal invasive assessment of uncertain mammography and MRI tomography findings. Zentralblatt Fur Chirurgie 123 (Suppl 5) 66-69.

Hill CR \& ter Haar GR 1995 High intensity focused ultrasound potential for cancer treatment. British Journal of Radiology 68 1296-1303.

Hill ADK, Tran KM, Adhurst T, Yeung H, Yeh SD, Rosen PP, Borgen PI \& Code HS III 1999 Lessons learned from 500 cases of lymphatic mapping for breast cancer. Annals of Surgery 229 $528-535$.
Hoey MF, Mulier PM \& Shake JG 1995 Intratumoral ablation using radiofrequency energy via screw-tip catheter and saline electrode. Pacing and Clinical Electrophysiology 18917.

Hortobagyi GN, Ames FC, Buzdar AU, Kau SW, McNeese MD, Paulus D, Hug V, Homes FA, Romsdahl MM \& Fraschini G 1988 Management of stage III primary breast cancer with primary chemotherapy, surgery, and radiation therapy. Cancer 62 2507-2516.

Hunt KK, Baldwin BJ, Strom EA, Ames FC, McNeese MD, Kroll SS \& Singletary SE 1997 Feasibility of postmastectomy radiation therapy after TRAM flap breast reconstruction. Annals of Surgical Oncology 4 377-384.

International (Ludwig) Breast Cancer Study Group 1990 Prognostic importance of occult axillary lymph node micrometastases from breast cancers. Lancet 335 1565-1568.

Jacobson JA, Danforth DN, Cowan H, d'Angelo T, Steinberg SM, Pierce L, Lippman ME, Lichter AS, Glatstein E \& Okunieff P 1995 Ten-year results of a comparison of conservation with mastectomy in the treatment of stage I and II breast cancer. New England Journal of Medicine 332 907-911.

Jeffrey SS, Birdwell RL, Ikeda DM, Daniel BL, Nowels KW, Dirbas FM \& Griffey SM 1999 Radiofrequency ablation of breast cancer. Archives of Surgery 134 1064-1068.

Kaplan JL \& Allen RJ 2000 Cost-based comparison between perforator flaps and TRAM flaps for breast reconstruction. Plastic and Reconstructive Surgery 105 943-948.

Kern KA 1999 Sentinel lymph node mapping in breast cancer using subareolar injection of blue dye. Journal of the American College of Surgeons 189 539-545.

Klimberg VS, Rubio IT, Henry R, Cowan C, Calvert M \& Korourian S 1999 Subareolar versus peritumoral injection for location of the sentinel lymph node. Annals of Surgery 229860 865 .

Koller M, Barsuk D, Zippel D, Engelberg S, Ben-Ari G \& Papa MZ 1998 Sentinel lymph node involvement - a predictor for axillary node status with breast cancer - has the time come? European Journal of Surgery 24 166-168.

Kollias J, Gill PG, Chatterton BE, Hall VE, Bochner MA, Coventry BJ \& Fasshid G 1999 Reliability of sentinel node status in predicting axillary lymph node involvement in breast cancer. Medical Journal of Australia 171 461-465.

Kraemer O, Andersen M \& Siim E 1996 Breast reconstruction and tissue expansion in irradiated versus not irradiated women after mastectomy. Scandinavian Journal of Plastic and Reconstructive Surgery and Hand Surgery 30 201-206.

Krag D, Weaver D, Ashikaga T, Moffat F, Klimberg VS, Shriver C, Feldman S, Kusminsky R, Gadd M, Kuhn J, Harlow S \& Beitxch P 1998 The sentinel node in breast cancer: a multicenter validation study. New England Journal of Medicine 339 941946.

Kroll SS 2000 Fat necrosis in free transverse rectus abdominis myocutaneous and deep inferior epigastric perforator flaps. Plastic and Reconstructive Surgery 106 576-583.

Kroll SS, Evans GRD, Reece GP, Miller MJ, Robb GL, Baldwin BH \& Schusterman MA 1996 Comparison of resource costs between implant-based and TRAM flap breast reconstruction. Plastic and Reconstructive Surgery 97 364-372.

Kuerer HM, Sahin AA, Hunt KK, Newman LA, Breslin TM, Ames FC, Ross MI, Buzdar AU, Hortobagyi GN \& Singletary SE 1999 Incidence and impact of documented positive to negative complete conversion of axillary lymph node metastases in breast 
cancer patients treated with neoadjuvant chemotherapy. Annals of Surgery 230 72-78.

Kurtz JM, Amalris R, Brandone H, Ayme Y \& Spilalier JM 1989a Local recurrence after breast-conserving surgery and radiotherapy. Cancer 63 1912-1917.

Kurtz JM, Jacquemier J, Torhorst J, Spitalier JM, Amalris R, Hunig R, Walther E, Harder F, Almendral A \& Brandone H $1989 b$ Conservation therapy for breast cancers other than infiltrating ductal carcinoma. Cancer 63 1630-1635.

Laronga C, Robb GL \& Singletary SE 1998 The feasibility of skin-sparing mastectomy with preservation of the nipple-areola complex. Breast Diseases, a Year Book Quarterly 9 125-127.

Laronga C, Kemp B, Johnston D, Robb GL \& Singletary SE 1999 The incidence of occult nipple-areola complex involvement in breast cancer patients receiving a skin-sparing mastectomy. Annals of Surgical Oncology 6 609-613.

Law TM, Hesketh PJ, Porter KA, Lawn-Tsao L, McAnaw R \& Lopez MJ 1996 Breast cancer in elderly women: presentation, survival, and treatment options. Surgical Clinics of North America 76 289-307.

Leopold KA, Recht A, Schnitt SJ, Connolly JL, Rose MA, Silver B \& Harris JR 1989 Results of conservative surgery and radiation therapy for multiple synchronous cancers of one breast. International Journal of Radiatation Oncology, Biology, Physics 16 11-16.

Lerman C, Hughes C, Croyle RT, Main D, Durham C, Snyder C, Bonney A, Lynch JF, Narod SA \& Lynch HT 2000 Prophylactic surgery decisions and surveillance practices one year following BRCA1/2 testing. Preventive Medicine 31 75-80.

Leveilee RJ, Hoey MG, Hulbert JH, Mulier P, Lee D \& Jessirun J 1996 Enhanced radiofrequency ablation of canine prostate utilizing a liquid conductor: the virtual electrode. Journal of Endocrinology 10 5-11.

Liberman L, LaTrenta LR, Van Zee KJ, Morris EA, Abramson AF \& Dershaw DD 1997 Stereotactic core biopsy of calcifications highly suggestive of malignancy. Radiology 203 673-677.

Lingos TI, Nixon AJ, Connolly JL, Schnitt S, Schneider L, Silver B, Recht A \& Harris JR 1995 Risk of local failure in breast cancer patients with 4 or more positive lymph nodes treated with breast-conserving surgery. International Journal of Radiation Oncology, Biology, Physics 32 (Suppl 1) 263.

Lossing C, Brongo S \& Holmstrom H 1998 Nipple reconstruction with a modified S-flap technique. Scandinavian Journal of Plastic and Reconstructive Surgery and Hand Surgery 32 275279.

Mansour EG, Gray R, Shatila AH, Osborne CK, Tormey DC, Gilchrest KW, Cooper MR \& Falkson G 1989 Efficacy of adjuvant chemotherapy in high-risk node-negative breast cancer: an intergroup study. New England Journal of Medicine 320 485490.

Matthews BD \& Williams GB 1999 Initial experience with the advanced breast biopsy instrumentation system. American Journal of Surgery 177 97-101.

Maunsell E, Brisson J \& Deshenes L 1993 Arm problems and psychological distress after surgery for breast cancer. Canadian Journal of Surgery 36 315-320.

Meiser B, Butow P, Friedlander M, Schnieden V, Gattas M, Kirk J, Suthers G, Haan E \& Tucker K 2000 Intention to undergo prophylactic bilateral mastectomy in women at increased risk of developing hereditary breast cancer. Journal of Clinical Oncology 18 2250-2257.
Meyer JE, Smith DN, DiPiro PJ, Denison CM, Frenna TH, Harvey SC \& Ko WD 1997 Stereotactic breast biopsy of clustered microcalcifications with a directional, vacuum-assisted device. Radiology 204 575-576.

Miao Y, Ni Y, Mulier S, Wang K, Hoey MF, Mulier P, Penninchx F, Yu J, De Scheerder I, Baert AL \& Marchal G 1997 Ex vivo experiment on radio-frequency liver ablation with saline infusion through a screw-tip cannulated electrode. Journal of Surgical Research 71 19-24.

Mirza AN, Fornage BD, Sneige N, Kuerer HM, Newman LA, Ames FC \& Singletary SE 2001a Radiofrequency ablation of solid tumors. Cancer Journal from Scientific American 1 95-102.

Mirza NW, Vlastos G, Meric F, Buchholz RA, Esnaola N, Singletary SE, Kuerer HM, Newman LA, Ames FC, Ross MI, Feig BW, Pollock RE, McNeese M, Strom E \& Hunt KK 2001b Predictors of locoregional recurrence among patients with early-stage breast cancer treated with breast-conserving therapy. Annals of Surgical Oncology (In Press).

Nelson H, Miller SH, Buck D, Demuth RJ, Fletcher WS \& Buehler P 1989 Effectiveness of prophylactic mastectomy in the prevention of breast tumors in $\mathrm{C} 3 \mathrm{H}$ mice. Plastic \& Reconstructive Surgery 83 662-669.

Nemoto T, Patel JK, Roxner D, Dao TL, Schuh M \& Penetrante R 1991 Factors affecting recurrence in lumpectomy without irradiation for breast cancer. Cancer 67 2079-2082.

Newman LA, Kuerer HM, Hunt KK, Kroll SS, Ames FC, Ross MI, Feig BW \& Singletary SE 1998 Presentation, treatment, and outcome of local recurrence after skin-sparing mastectomy and immediate breast reconstruction. Annals of Surgical Oncology 5 $620-626$.

Ng PC, Chua AC, Lannin DP, van Eyk JJ, Swanton MS \& Tafra L 1999 Age and surgeon experience: the only significant factors contributing to sentinel node mapping failure in breast cancer. Breast Cancer Research and Treatment 5727 (Abstract 12).

Noguchi M, Motomura K, Imoto S, Miysuchi M, Sato K, Iwata K, Ohta M, Kuronumi M \& Tangawa K 1999 Axillary dissection can be avoided by sentinel lymph node biopsy in small breast cancer: a multicentric study by the Japanese Breast Cancer Society. Breast Cancer Research and Treatment 5739 (Abstract 118).

O’Neil S, Castelli M, Gattuso P, Kluskens L, Madsen K \& Aranha G 1997 Fine-needle aspiration of 697 palpable breast lesions with histopathologic correlation. Surgery 122 824-828.

Osborne MP, Ormiston N, Harmer CL, McKinna JA, Baker J \& Greening WP 1984 Breast conservation in the treatment of early breast cancer. A 20-year follow-up. Cancer 53 349-355.

Osborne MP, Borgen PI, Wong GY, Rosen PP \& McCormick B 1992 Salvage mastectomy for local and regional recurrence after breast-conserving operation and radiation therapy. Surgery, Gynecology and Obstetrics 174 189-194.

Payne DK, Biggs C, Tran KN, Borgen PI \& Massie MJ 2000 Women's regrets after bilateral prophylactic mastectomy. Annals of Surgical Oncology 7 150-154.

Pennisi VR \& Capozzi A 1989 Subcutaneous mastectomy data: final statistical analysis of 1500 patients. Aesthetic Plastic Surgery 13 15-21.

Peoples G, Heaton K, Booser D, Strom E, Singletary E, Ames F, Ross M, Feig G, Hortobagyi G \& Hunt K 1998 Breast conservation therapy for large primary and locally advanced breast cancers after induction chemotherapy. Proceedings of the Society of Surgical Oncology, San Diego, March 1998. 
Petrek JA 1994 Breast cancer and pregnancy. National Cancer Institute Monographs, pp 113-121.

Petrek JA, Dukoff R \& Rogatko A 1991 Prognosis of pregnancy-associated breast cancer. Cancer 67 869-872.

Pierce SM, Recht A, Lingos TI, Abner A, Vicini F, Silver B, Herzog A \& Harris JR 1992 Long-term radiation complications following conservative surgery and radiation therapy in patients with early stage breast disease. International Journal of Radiation Oncology, Biology, Physics 23 915-923.

Pierce LJ, Strawderman M, Narod SA, Oliviotto I, Eisen A, Dawson L, Gaffney D, Solin LJ, Nixon A, Garber J, Berg C, Isaacs C, Heimann R, Olopado OI, Haffty B \& Weber BL 2000 Effect of radiotherapy after breast-conserving treatment in women with breast cancer and germline BRCA1/2 mutations. Journal of Clinical Oncology 18 3360-3369.

Pijnappel RM, van Dalen A, Rinkes IH, van den Tweel JH \& Mali WP 1997 The diagnostic accuracy of core biopsy in palpable and non-palpable breast lesions. European Journal of Radiology 24 120-123.

Portincasa G, Lucci E, Navarra GG, Donato S, Parpanesi R \& Garcea D 2000 Initial experience with breast biopsy utilizing the Advanced Breast Biopsy Instrumentation (ABBI). Journal of Surgical Oncology 74 201-203.

Rabin Y, Julian TB, Olson P, Taylor MJ \& Wolmark N 1999a Development of a cryosurgical technique for breast malignancies. SPIE Proceedings (International Society of Optical Engineering) $3590465-471$.

Rabin Y, Julian TB, Olson P, Taylor MJ \& Wolmark N $1999 b$ Long-term follow-up post-cryosurgery in a sheep breast model. Cryobiology 39 29-46.

Reynolds C, Mick R, Donohue JH, Grant CS, Farley DR, Carlans LS, Orel SG, Keeney GL, Lawton TJ \& Czerniecki BJ 1999 Sentinel lymph node biopsy with metastasis: can axillary dissection be avoided in some patients with breast cancer? Journal of Clinical Oncology 17 1720-1726.

Robb GL 2000 Skin-sparing mastectomy and immediate reconstruction. In Advanced Therapy of Breast Disease, Ch. 22, pp $200 \&$ 207. Eds Singletary SE \& Robb GL. Hamilton, Ontario: B.C. Decker Inc.

Robertson JG, Clarke DH, Pevzner MM \& Matter RC 1991 Breast conservation therapy: severe breast fibrosis after radiation therapy in patients with collagen-vascular disease. Cancer $\mathbf{6 8}$ 502-508.

Robinson DS, Parel JM, Denham DB, Manns F, Gonzalez X, Schachner R, Herron A \& Burdette EC 1996 Stereotactic uses beyond core biopsy: model development for minimally invasive treatment of breast cancer through interstitial laser hyperthermia. American Surgeon 62 117-118.

Robinson DS, Parel JM, Denham DB, Gonzalez-Cirre X, Manns F, Milne PJ, Schachner RD, Herron AJ, Commander J \& Hauptmann G 1998 Interstitial laser hyperthermia model development for minimally invasive therapy of breast carcinoma. Journal of the American College of Surgeons 186 284-292.

Robinson DS 2000 Minimally invasive therapy of primary breast cancer. In Matching the Energy Source to the Clinical Need, pp 281-293. Ed TP Ryan. Bellingham, Washington: SPIE Optical Engineering Press.

Robson M, Levin D, Federici M, Satagopan J, Bogolminy F, Heirdt A, Borgen P, McCormick B, Hudis C, Norton L, Boyd J \& Offit K 1999 Breast conservation therapy for invasive breast cancer in Ashkenazi women with BRCA gene founder mutations. Journal of the National Cancer Institute 912112 2117.

Rui J, Tatsutani KN, Dayiya R \& Rubinsky B 1999 Effect of thermal variables on human breast cancer in cryosurgery. Breast Cancer Research and Treatment 53 185-192.

Sarrazin D, Le MG, Arriagada R, Contesso G, Fontaine F, Spielmann M, Rochard F, Le Chevalier T \& Lacour J 1989 Ten-year results of a randomized trial comparing a conservative treatment to mastectomy in early breast cancer. Radiotherapy and Oncology 14 177-184.

Schusterman MA, Kroll SS, Miller MH, Reece GP, Baldwin BH, Robb GL, Altmyer CS, Ames FC, Singletary SE \& Ross MI 1994 The free transverse rectus abdominis musculocutaneous flap for breast reconstruction: one center's experience with 211 consecutive cases. Annals of Plastic Surgery 32 234-241.

Schwartzberg BS, Goates JJ, Keeler SA \& Moore JA 2000 Use of advanced breast biopsy instrumentation while performing stereotactic breast biopsies: review of 150 consecutive biopsies. Journal of the American College of Surgeons 191 9-15.

Scopa CD, Koukouras D Spiliotis J, Harkoftakis J, Koureleas S, Kyriakopoulou D \& Tzoracolefth A 1996 Comparison of fine needle aspiration and Tru-Cut biopsy of palpable mammary lesions. Cancer Detection and Prevention 20 620-624.

Sedmak DD, Meineke TA, Knechtges DS \& Anderson J 1989 Prognostic significance of cytokeratin-positive breast cancer metastases. Modern Pathology 2 516-520.

Sheth D, Wesen CA, Schroder D, Boccaccio JE \& Lloyd LR 1999 the advanced breast biopsy instrumentation experience at a community hospital. American Surgeon 65 726-729.

Simon JR, Kalbhen CL, Cooper RA \& Flisak ME 2000 Accuracy and complication rates of US-guided vacuum-assisted core breast biopsy: initial results. Radiology 215 694-697.

Singletary SE 1998 Management of the axilla in early stage breast cancer. In American Society of Clinical Oncology Educational Book, pp 132-141. Ed. MC Perry. Alexandria VA: American Society of Clinical Oncology.

Singletary SE, McNeese MD \& Hortobagyi GN 1992 Feasibility of breast conservation surgery after induction chemotherapy for locally advanced breast carcinoma. Cancer 69 2849-2852.

Smith ML, Gregory RD, Evans MD, Gurech K, Bouvet M, Singletary SE, Ames FC, Janjan N \& McNeese MD 1998 Reduction mammoplasty: its role in breast conservation surgery for early stage breast cancer. Annals of Plastic Surgery 41234 239.

Society of Surgical Oncology. 1993 SSO develops position statement on prophylactic mastectomies. SSO News Summer edn.

Spear SL \& Arias J 1995 Long-term experience with nipple-areola tattooing. Annals of Plastic Surgery 35 232-236.

Staren ED, Sabel MS, Gianakakis LM, Wiener GA, Hart VM, Gorski M, Dowlatshahi K, Corning BG, Haklin MF \& Koukoulis G 1997 Cryosurgery of breast cancer. Archives of Surgery 132 28-33.

Tanabe HY, Tai Y, Kiyokawa K \& Yamauchi T 1997 Nipple-areola reconstruction with a dermal-fat flap and rolled auricular cartilage. Plastic and Reconstructive Surgery 199431 438.

Trojani M, de Mascarel I, Bonichon F, Coindre JM \& Delsol G 1987 Micrometastases to axillary lymph nodes from carcinoma of breast: detection by immunohistochemistry and prognostic significance. British Journal of Cancer 55 303-306. 
Van der Vange N \& van Dongen JA 1991 Breast cancer and pregnancy. European Journal of Surgical Oncology 17 1-8.

Vasen HF, Haites NE, Evans DG, Steel CM, Moller P, Hodgson S, Eccles D, Morrison P, Stoppa Lyonet D, Chang-Claude J \& Caligo M 1998 Current policies for surveillance and management in women at risk of breast and ovarian cancer: a survey among 16 European family cancer clinics. European Familial Breast Cancer Collaborative Group. European Journal of Cancer 34 1922-1926.

Vega A, Garijo F \& Ortega E 1995 Core needle aspiration biopsy of palpable breast masses. Acta Oncologica 34 31-34.

Verblanc KM, Fleming TP, Min CH, Purser SM \& Tafra L 1999 RT-PCT increases detection of breast cancer sentinel lymph node micrometastases. Breast Cancer Research and Treatment 5741 (Abstract 125).

Verhoog LC, Brekelmans CT, Seynaeive C, Dahmen G, Van Geel AN, Bartels CC, Tilanus-Linthorst MM, Wagner A, Devilee P, Halley DJ, Van den Ouiveland AM, Meijers-Heijboer EJ \& Klijn JG 1998 Survival and tumor characteristics of breast cancer patients with germline mutations of BRCA1. Lancet 351 316-321.

Veronesi U, Luini A, Galimberti V \& Zurrida S 1994 Conservation approaches for management of stage I/II carcinoma of the breast: Milan Cancer Institute Trials. World Journal of Surgery 1870 75.

Veronesi U, Salvadori B, Luini A, Greco M, Saccozzi R, del Vecchio M, Mariani L, Zurrida S \& Rilke F 1995 Breast conservation is a safe method in patients with small cancer of the breast. Long-term results of three randomized trials on 1973 patients. European Journal of Cancer 31A 1574-1579.

Veronesi U, Paganelli G, Viale G, Galimbert V, Luini A, Zurrida S, Robertson C, Sacchini V, Veronesi P, Orvieto E, De Cicco C, Intra M, Tosi G \& Scarpa D 1999 Sentinel lymph node biopsy and axillary dissection in breast cancer: results in a large series. Journal of the National Cancer Institute 91 368-373.

Victor SJ, Brown DM, Horwitz EM, Martinez AA, Kini VR, Pettinga JE, Shaheen KW, Benitez P, Chen PY \& Vicini FA 1998 Treatment outcome with radiation therapy after breast augmentation or reconstruction in patients with primary breast carcinoma. Cancer 82 1303-1309.

Vlastos G, Rubio IT, Mirza NW, Newman LA, Aurora R, Alderfer J, Buzdar AU \& Singletary SE 2000 Impact of multicentricity on clinical outcome in patients with T1-2, N0-1, M0 breast cancer. Annals of Surgical Oncology 7 581-587.

Vlastos G, Mirza NQ, Meric F, Hunt KK, Kuerer HM, Ames FC, Ross MI, Bucholz TA, Hortobagyi GN \& Singletary SE 2001 Breast conservation therapy as a treatment option for the elderly: The M.D. Anderson Experience. Cancer (In Press).

Voogd AC, van Tienhoven G, Peterse Hl, Crommelin MA, Rutgers EJ, van de Velde CJ, van Geel BN 1999 Local recurrence after breast conservation therapy for early stage breast carcinoma: detection, treatment, and outcome in 266 patients. Dutch Study Group on Local Recurrence after Breast Conservation (BORST). Cancer 85 437-446.

Weibe VJ \& Sipila PEJ 1994 Pharmacology of antineoplastic agents in pregnancy. Critical Reviews in Oncology/Hematology $1675-112$.

Weiss MC, Fowble BL, Solin LJ, Yeh IT \& Schultz DJ 1992 Outcome of conservative therapy for invasive breast cancer by histologic subtype. International Journal of Radiation Oncology, Biology, Physics 23 941-947.

Wheeler JE, Enterline HT, Roseman JM, Tomasulo JP, McIlvaine CH, Fitts WT Jr \& Kirschenbaum J 1974 Lobular carcinoma in situ of the breast. Long-term follow-up. Cancer 34 554-563.

Williams JK, Carlson GW, Bostwick J III, Bried JT \& Mackay G 1997 The effects of radiation treatment after TRAM flap breast reconstruction. Plastic and Reconstructive Surgery $1001153-$ 1160.

Wong JH, Jackson CF, Swanson JS, Palmquist MA, Oyama AA, Miller SH \& Fletcher WS 1986 Analysis of the risk reduction of prophylactic partial mastectomy in Sprague-Dawley rats with 7,12-dimethylbenzanthracene-induced breast cancer. Surgery 99 67-71.

Ziegler LD \& Kroll SS 1991 Primary breast cancer after prophylactic mastectomy. American Journal of Clinical Oncology 14 451-454. 